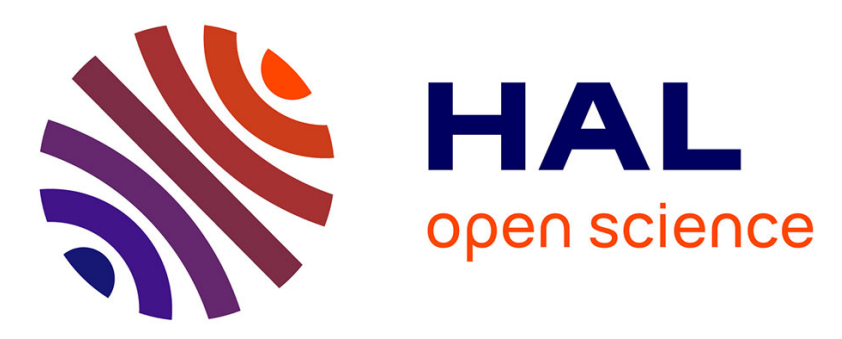

\title{
Hydrogen diffusion process in the oxides formed on Zirconium Alloys during corrosion in Pressurized Water Reactor Conditions
}

Marc Tupin, Frantz Martin, Caroline Bisor, Romain Verlet, Philippe Bossis, Jacques Chêne, François Jomard, Pascal Berger, Serge Pascal, Nicolas Nuns

\section{To cite this version:}

Marc Tupin, Frantz Martin, Caroline Bisor, Romain Verlet, Philippe Bossis, et al.. Hydrogen diffusion process in the oxides formed on Zirconium Alloys during corrosion in Pressurized Water Reactor Conditions. Corrosion Science, 2016, 116, pp.1-13. 10.1016/j.corsci.2016.10.027 . cea-01465798

\section{HAL Id: cea-01465798 https://hal-cea.archives-ouvertes.fr/cea-01465798}

Submitted on 13 Feb 2017

HAL is a multi-disciplinary open access archive for the deposit and dissemination of scientific research documents, whether they are published or not. The documents may come from teaching and research institutions in France or abroad, or from public or private research centers.
L'archive ouverte pluridisciplinaire HAL, est destinée au dépôt et à la diffusion de documents scientifiques de niveau recherche, publiés ou non, émanant des établissements d'enseignement et de recherche français ou étrangers, des laboratoires publics ou privés. 


\section{Hydrogen diffusion process in the oxides formed on Zirconium Alloys during corrosion in Pressurized Water Reactor Conditions}

Marc TUPIN ${ }^{1}$, Frantz MARTIN ${ }^{2}$, Caroline BISOR ${ }^{1}$, Romain VERLET ${ }^{1}$, Philippe BOSSIS ${ }^{1}$, Jacques CHENE ${ }^{3}$, François JOMARD ${ }^{4}$, Pascal BERGER ${ }^{5}$, Serge PASCAL ${ }^{6}$, Nicolas NUNS ${ }^{7}$

${ }^{1}$ DEN-Service d'Etudes des Matériaux Irradiés, CEA, Université Paris-Saclay, F-91191, Gifsur-Yvette, France

${ }^{2}$ DEN-Service de la Corrosion et du Comportement des Matériaux dans leur Environnement CEA, Université Paris-Saclay, F-91191 Gif-sur-Yvette Cedex, France ${ }^{3}$ CNRS/CEA UMR 8587, CEA Saclay, F-91191, Gif-sur-Yvette, France ${ }^{4}$ CNRS UMR 8635, GEMaC, 92195 Meudon cedex, France,

${ }^{5}$ NIMBE, CEA, CNRS, Université Paris-Saclay, CEA Saclay 91191 Gif sur Yvette Cedex ${ }^{6}$ DEN-Service d'Etudes Mécanique et Thermique, CEA, Université Paris-Saclay, F-91191, Gif-sur-Yvette, France, CEA/Saclay, 91191 Gif-sur-Yvette cedex, France,

${ }^{7}$ IMMCL Chevreul, Université Lille 1 Science et Technologie, 59655 Villeneuve d'Ascq cedex, France,

Corresponding author : Marc Tupin Tel/Fax : + 33 (1) 6908 88 69/90 73_marc.tupin@cea.fr 


\title{
Highlights for Editors,
}

To better understand the $\mathrm{H}$ uptake process by zirconium alloy during corrosion in PWR conditions, experiments such as corrosion tests, isotopic tracer exposure followed by SIMS analyses, ERDA measurements and Thermal Desorption Spectroscopy showed that :

- the oxide film in pre-transition is divided into two sub-layers, an external one, highly permeable to hydrogen and an inner protective one.

- the pre-transition oxide layer presents two H-oxide interaction sites in consistency with the subdivision of the oxide layer.

- apparent diffusion coefficient of hydrogen in the inner oxide was estimated around $2.10^{-14}$ $\mathrm{cm}^{2} / \mathrm{s}$ at $360^{\circ} \mathrm{C}$.

\begin{abstract}
(100 words)
During the corrosion in primary water of zirconium alloys, a fraction of hydrogen from the water diffuses through the oxide into the alloy. To better understand the hydriding process, isotopic tracers and SIMS experiments were performed on oxides grown on Zircaloy-4 alloy under simulated primary water conditions. Results showed the oxide film in pre-transition is divided into two sub-layers, an external one, highly permeable to hydrogen and an inner protective one. Thermal Desorption Spectroscopy analyses revealed two interaction sites of hydrogen, located in each oxide sublayer.

Apparent diffusion coefficients of hydrogen in both oxide sublayers were estimated with different methods.
\end{abstract}




\section{Introduction}

In Pressurized Water Reactors, zirconium alloys are used as fuel cladding materials. These claddings represent the first containment barrier to fission products. Its mechanical integrity has to be ensured during their life cycle. These fuel claddings are exposed in service to aggressive aqueous environment $\left(285-325^{\circ} \mathrm{C}, 15.5 \mathrm{MPa}, 0.7\right.$ to 2.2 wt. ppm $\mathrm{Li}$ and 10 to 1200 wt. ppm B). In these conditions, the corrosion kinetics of Zircaloy-4 (Zr-1.3Sn-0.2Fe-0.1Cr) shows a drastic acceleration phase referred as "high burnup acceleration" which occurs for fuel burnups above $35 \mathrm{GWd} / \mathrm{tU}$ [1]. As a consequence, the corrosion of Zircaloy-4 (often referred to afterward as Zy4) is one of the main limiting factors of the fuel rod life time.

The kinetic acceleration at high burnup could be due to the evolution of the tin distribution in the alloy in service [2-4] or to the irradiation effect of the material leading to the amorphization of the $\mathrm{Zr}(\mathrm{Fe}, \mathrm{Cr})_{2}$ precipitates and the iron dissolution in the matrix [5-7]. The oxide irradiation could be also involved in the oxidation rate increase of Zircaloy-4 cladding in reactor [7-10]. On the other hand, several authors suggested that this enhanced corrosion rate would be rather due to the precipitation of numerous hydrides at the metal/oxide interface in the metallic part of the cladding [11-14]. Indeed, during the corrosion in primary water, a fraction of the hydrogen from the water involved in the oxidation reaction ingresses into the alloy through the oxide. In the metallic matrix, once the solubility limit is reached at the irradiation temperature, hydrogen precipitates as zirconium hydrides mainly located just under the metal/oxide interface due to the thermal gradient across the cladding. To clarify the role of hydrides, many studies dealt with the effect of the hydride precipitation on the Zy-4 corrosion behavior. They typically showed a higher oxidation rate of hydride phase compared with the $\alpha-\operatorname{Zr}$ matrix $[11,12,15]$ and a significant change in the oxide structure and/or microstructure [11-17]. In relation with these investigations, several studies tried to determine the hydrogen pick-up mechanism by the metal. It is usually assumed that this process is 
controlled by the hydrogen diffusion through the oxide layer. As a consequence, the diffusion coefficient of hydrogen in the corrosion film using isotopic tracers [18-20] as well as the localisation of the water molecule dissociation [21, 22] were studied in the past. However, due to the presence of two sub-layers in the oxide with different hydrogen transport properties [18], hydrogen diffusion coefficient is quite difficult to calculate accurately from measurements.

The aims of this work are consequently to enhance the understanding of the hydrogen uptake process and to propose methods for estimating hydrogen diffusion coefficients in the oxide.

In this sense, transport properties of hydrogen in oxides were studied using isotopic tracers and SIMS analyses. Interaction sites of hydrogen in oxide layers were characterized with Thermal Desorption Spectroscopy. Elastic Recoil Detection Analysis (ERDA) technique was finally used to measure hydrogen concentration in the oxide. The last part of this paper is devoted to the calculations of apparent diffusion coefficients with different methods.

\section{Experimental}

\subsection{Materials}

Sheets of recrystallized Zircaloy-4 (Zy4) supplied by AREVA NP were used. The chemical composition of the alloy is given in table 1 . The specimens were cut from a $0.45 \mathrm{~mm}$-thick cold-worked sheet which was submitted to a final thermal treatment of recrystallization at $700^{\circ} \mathrm{C}$ during 2 hours. The alloy microstructure is characterized by an average grain size of about $10 \mu \mathrm{m}$. The samples were just cleaned in acetone-alcohol solution and finally rinsed in deionized water. No specific surface preparation was performed.

- Table 1 - 
Table 1 : Chemical composition of Zircaloy-4 sheet (wt\%)

\subsection{Corrosion tests}

Zircaloy-4 samples were corroded in static autoclaves at $360^{\circ} \mathrm{C}$ and $18.7 \mathrm{MPa}$ in primary water up to 170 days to reach the post-transition kinetic regime. The primary water chemistry was composed of 2 wt. ppm of lithium and 1000 wt. ppm of boron issued from, respectively, lithium hydroxide and boric acid.

Then, to understand the hydrogen pickup mechanism of this material, the hydrogen diffusion in the oxide was followed using deuterium $\left({ }^{2} \mathrm{H}\right)$ as an isotopic tracer. The specimens were so corroded in heavy water, ${ }^{2} \mathrm{H}_{2} \mathrm{O},\left(360^{\circ} \mathrm{C}, 18.7 \mathrm{MPa}, 2 \mathrm{ppm} \mathrm{Li}, 1000 \mathrm{ppm} \mathrm{B}\right)$ during short $(6,24$ hours) or long (7 days) exposure times.

After corrosion test, fusion measurements were carried out to estimate the hydrogen uptake of the samples. The experimental procedure is detailed in Table 2.

\section{- Table 2 -}

\subsection{Sample characterization}

Penetration profiles of hydrogen, deuterium, oxygen and zirconium in the oxide scales were analyzed by Secondary Ion Mass Spectrometry (SIMS) using a CAMECA IMS 4F system with a $10 \mathrm{keV}$ energetic $\mathrm{Cs}^{+}$primary ion beam. Negative secondary ions were collected from an analyzed surface of $33 \mu \mathrm{m}$ in diameter with a low weight resolution mode. SIMS profiles obtained after deuterium extraction by Thermal Desorption Spectroscopy (TDS) were performed with a TOF-SIMS 5 instrument (IONTOF, GmbH, Münster, Germany) with $2 \mathrm{keV}$ energy $\mathrm{Cs}^{+}$ions for sputtering and a $25 \mathrm{keV}$ energy $\mathrm{Bi}^{+}$ions for analysis. The crater has a size of $200 \mu \mathrm{m} \times 200 \mu \mathrm{m}$ and the analyzed area was $70 \mu \mathrm{m} \times 70 \mu \mathrm{m}$. 
Secondly, the average hydrogen concentrations in the oxide were measured by Elastic Recoil Detection Analysis (ERDA) using a nuclear microprobe. Measurements have been performed using a $8 \times 2 \mu \mathrm{m}^{2}$ beam size on a cross section of the oxide scale obtained by $10^{\circ}$ angle slant cutting in order to maximize the analysed surface. During this experiment, the target is impacted by a helium ion beam with an energy of $3 \mathrm{MeV}$ and an incidence angle of $15^{\circ}$. After elastic diffusion in the sample, the backscattered $\mathrm{He}^{4+}$ and the ejected protons are collected by a detector measuring their energies (cf. Figure 16a). Hydrogen measurements are calibrated using Kapton ${ }^{\circledR}$ with a known hydrogen content [23]. The use of Kapton ${ }^{\circledR}$ to calibrate the ERDA technique were validated with measurements on massive hydrides.

Fusion measurements, giving global hydrogen amount of the samples, were made using a HMAT 2500 Ströhlein type analyser and a FEG SEM ZEISS ULTRA 55 microscope was used to characterize the oxide films formed on the samples during corrosion tests.

Thermal Desorption Spectroscopy (TDS) set-up used in this study was entirely designed in the LECA laboratory (CEA, France) and is made of a quartz tube under vacuum (lower limit $10^{-8}$ mbar) inserted in a cylindric furnace coupled to a quadripolar mass spectrometer (INFICONTM). This device enables, using a temperature ramp, to desorb and quantify the hydrogen or deuterium trapped in a material. It is a very sensitive tool to follow the hydrogen or deuterium desorption rate from a speciemen. The investigated temperature range is between $300 \mathrm{~K}$ to $1073 \mathrm{~K}$ since no release of deuterium is observed beyond. The signal corresponding to ${ }^{2} \mathrm{H}_{2}{ }^{+}$(m/z ratio of 4$)$ was corrected from the deuterium natural content $\left({ }^{2} \mathrm{H} /{ }^{1} \mathrm{H}=1.5 \times 10^{-4}\right)$ and the recombination factor in the spectrometer and finally normalized to the mass of the TDS sample for further comparison of the samples with each other. Finally, calibrated ${ }^{2} \mathrm{H}_{2}$ leaks were used to calibrate the TDS experiment. The samples analysed by this technique are indicated in Table 2. 


\section{Results and discussion}

\subsection{Corrosion test results : kinetics and oxide microstructure}

The corrosion behaviour of Zircaloy- 4 was studied at $360^{\circ} \mathrm{C}$ in simulated PWR environmental conditions in an autoclave (i. e. without irradiation). The kinetic curves obtained with $\mathrm{Z} 2$ and Z8 sample are presented in Figure 1. According to literature data, it is well known that the pre-transition stage of the corrosion process of Zircaloy-4 is characterized by the growth of a dense and protective oxide layer controlled by a diffusion step of oxygen [24, 25]. The oxidation kinetics of zirconium alloys follows a kinetic law usually fitted by a power law (Eq. 1) :

$x=k t^{n}$

with an exponent $\mathrm{n}$ lower than 0.5 , depending on the material [21].

The experimental points on both samples are reproducible and fitted during the pre-transition stage with the law described by (Eq. 2):

$x=0.47 t^{0.3}$

with $x$ the oxide thickness $(\mu \mathrm{m})$ and $t$ the corrosion exposure time (days).

The value of the exponent $\mathrm{n}$ is very close to that obtained by A. Couet for Zy4 sheets [26].

\section{-Figure 1-}

Beyond the kinetic transition occurring for an oxide thickness of around $2 \mu \mathrm{m}$, the outer part of the oxide becomes cracked [27-28] and partially porous [29-31] whereas a new protective film is built at the metal/oxide interface. Hence, in the post-transition stage, the oxide is divided into two sub-layers. The external one formed during the first kinetic regime presents some defects as pores and cracks. The inner part of the oxide is theoretically a protective layer. However, this protective part is not clearly observed on the micrograph of Figure 2. In 
this post-transition region, a new corrosion cycle occurs. It can be fitted with a similar power law as (Eq. 1). The experimental points of Z8 sample obtained during 171 days of corrosion are reported in figure 1 and are also close to the fitting curve (continuous line).

The hydrogen amounts absorbed during the corrosion process were also measured before (Z3 sample, $1.6 \mu \mathrm{m}$ oxide thickness) and after (Z6 sample, $3.6 \mu \mathrm{m}$ oxide thickness) the kinetic transition. The hydrogen pickup ratio, $r_{\mathrm{h}}$, describes the fraction of absorbed hydrogen compared with the theoretical hydrogen amount that should be desorbed during the reduction of the water. It is calculated with the following formula (Eq. 3):

$$
r_{\mathrm{h}}=100 \frac{M_{\mathrm{ZrO}_{2}} \rho_{\mathrm{Zr}}}{2 M_{\mathrm{H}_{2}} \rho_{\mathrm{ZrO}_{2}}}\left(10^{-6}\left(H_{\mathrm{f}}-H_{\mathrm{i}}\right)\right) \frac{e_{\mathrm{i}}}{e_{\mathrm{ox}}}
$$

where $\rho_{\mathrm{zr}}$ is the density of zirconium $\left(\mathrm{g} / \mathrm{cm}^{3}\right), M_{\mathrm{H} 2}$ the molar mass of hydrogen gas $(\mathrm{g} / \mathrm{mol}), H_{\mathrm{f}}$ the mass quantity (wt. ppm) measured after corrosion test (normalized to one side of the sheet), $H_{\mathrm{i}}$ the initial amount of hydrogen in the sheet (10 wt. ppm), $e_{\mathrm{i}}$ the initial thickness of the specimen $(\mu \mathrm{m})$ and $e_{\mathrm{ox}}$ the oxide thickness $(\mu \mathrm{m})$.

The results are gathered in Table 3. Hydrogen uptake for $1.6 \mu \mathrm{m}$ oxide thickness is 12 wt. ppm corresponding to an hydrogen concentration in the material, $C_{\mathrm{H}_{-} \text {fusion }}^{\mathrm{Zr} \text {, } \mathrm{ZrO}_{2}}$, equal to to $7.8 \times 10^{-5}$ mol.cm $\mathrm{cm}^{-3}$. The hydrogen pickup ratio $\left(\mathrm{r}_{\mathrm{h}}\right)$ is in this case around $12 \%$. It means $12 \%$ only of the total hydrogen involved in the oxidation process diffuses in the oxide layer to reach the metal. This fraction is in good agreement with literature, more specifically between $5 \%$, measured by A. Couet [26], and 20\% reported by B. Cox [32].

\section{- Table 3 -}

Cross sections of the oxide films formed on samples after 50 and 171 days of corrosion at $360^{\circ} \mathrm{C}$ were prepared and observed by SEM in Secondary Electron mode. Micrographs are 
presented in Figure 2. At the SEM scale, the microstructure of the oxide grains during the pretransition stage is columnar with a main orientation roughly perpendicular to the metal/oxide interface and an average dimension of the columns of about $200 \mathrm{~nm}$ in length and $30 \mathrm{~nm}$ in diameter. This observation is consistent with previous studies [34-36].

\section{-Figure 2-}

\subsection{Transport properties of hydrogen in the oxide layers}

\subsubsection{Steady-state hydrogen distribution in the oxide during the pre-transition regime}

After the corrosion tests in primary water, the specimens were analyzed using SIMS technique. The ${ }^{16} \mathrm{O}$ concentration in the oxide is the same for all the analyzed samples. We consider that the ${ }^{16} \mathrm{O}$ SIMS intensity in the oxide reflects the secondary ion emission current. We try as far as possible that the ${ }^{16} \mathrm{O}$ SIMS intensity is around $5 \times 10^{7}$ counts per second $(\mathrm{cs} / \mathrm{s})$. To be comparative, all the profiles were corrected by a factor equal to the ratio between $5.10^{7}$ $\mathrm{cs} / \mathrm{s}$ and ${ }^{16} \mathrm{O}$ raw intensity really measured on each specimen (cf. Figure 4a).

Oxygen and hydrogen profiles obtained after 50 days are given in Figure 3 as a function of the abrasion time. In the oxide (stable constant ${ }^{16} \mathrm{O}$ signal), the slope change on the hydrogen profile observed at $200 \mathrm{~s}$ seems to indicate that the oxide layer may be divided into two parts, an external sublayer and an internal one.

\section{- $\quad$ Figure 3}

In the metallic part of the SIMS profile (cf. Figure 3), the hydrogen profile exhibits a high heterogeneous distribution of hydrogen, probably due to the hydride precipitation during the cooling step of the autoclave (Note that the hydrogen solubility limit is indeed very low at 
room temperature (few wt. ppm) [37]). This observation is confirmed by the hydrogen ionic image of the crater after abrasion by the SIMS primary ion beam presented in the insert of Figure 3, which highlights the over-concentrated hydrogen zones in the metal where the hydrides precipitated. The part of the SIMS profile in the alloy is consequently not exploitable.

Figure $4 \mathrm{a}$ focuses on the hydrogen profiles found in the oxide layer only. Since in both abovementioned oxide sublayers, the hydrogen concentration profile is linearly decreasing and reaching the metal/oxide interface (concentration gradient), it is highly probable that the steady-state was achieved after a 50-days exposure. For this reason, it is not possible to get any information on the hydrogen transport properties based only on such SIMS profiles. Dedicated experiments coupling short exposure times and the use of deuterium as isotopic tracer for hydrogen were thus carried out, in order to snapshoot the effective diffusion profiles of hydrogen (deuterium) in this oxide layer, representative of exposures at $360^{\circ} \mathrm{C}$. The use of deuterium, via heavy water, will provide more accurate concentration profiles, really representative of the exposure time, since its natural abundance is very low compared to hydrogen, one is pretty sure that the detected deuterium was inserted in the material during the dedicated experiment.

Moreover, in order to further be able to estimate any diffusion coefficient in the oxide layer, a preliminary step consists in the conversion of ionic abrasion time into a distance from the surface.

First, it was assumed that the metal/oxide interface on the profiles is positioned at the midheight of ${ }^{16} \mathrm{O}$ maximum intensity in the oxide (cf. Figure 4a). Second, knowing the oxide thickness, deduced from the weight gain (1.6 $\mu \mathrm{m}$ here), and considering a constant abrasion rate in the oxide, abrasion time - to - distance from the surface conversion can easily be made, as shown in Figure 4b. 


\section{- Figure 4a}

\section{- Figure 4b}

According to Figure $4 \mathrm{~b}$, the thicknesses of the sub-layers mentioned previously are around a few hundred nanometers for the external one and around $1 \mu \mathrm{m}$ for the internal one. . In literature, the same sub-division was reported in terms of hydrogen transport properties [18]. These sub-layers could be associated with the microstructure of the oxide scale described by A. Motta et al. [33]. In particular, the outer layer might correspond to the small equiaxe grain sublayer beneath the surface and the inner one to the columnar crystallites layer $[18,33]$. Unfortunately, our micrographs (Figure 2) do not really evidence the outer sublayer microstructure made of small equiaxe grains.

\subsubsection{Diffusion profiles of deuterium}

\section{Pre-transition stage}

To improve the understanding of the hydrogen pickup mechanism and better estimate the hydrogen diffusion rate in both sublayers, 3 identically pre-oxidized samples underwent different exposure times in heavy water (same experimental conditions). The associated thermal treatments are schematically indicated in Figure 5a. It is worth noting that during these thermal treatments, the oxide growth is negligible compared to its initial thickness, which allows us, at first order, to focus only on hydrogen/deuterium diffusion phenomena decoupled from oxide growth. The deuterium profiles in the oxide layers were obtained by SIMS analyses and are exposed in Figure 5b. They exhibit two features :

- The 3 profiles superimpose each other in the vicinity of the oxide surface down to roughly $300 \mathrm{~nm}$; 
- They then split to typical diffusion profiles depending on isothermal exposure durations at $360^{\circ} \mathrm{C}$, towards the metal/oxide interface.

In agreement with the previous results obtained on hydrogen, the deuterium profiles allow to divide the oxide layer in two domains regarding behaviour toward deuterium mobility : (i) a first down to $300 \mathrm{~nm}$ beneath the surface which seems quickly crossed by deuterium, since its steady state concentration gradient seems already established, and (ii) an inner sublayer where transport may be limited by diffusion.

\section{-Figure 5-}

In addition, a close look at the curve of the Thermal Transient sample (called ZD_TT on Figure $4 \mathrm{~b}$ ) shows that even without holding the specimen at high temperature, deuterium has already reached the internal layer. Deuterium diffusivity in the external layer $(x<300 \mathrm{~nm})$ is therefore quite high, at least compared to the one in the inner part of the oxide. Besides, the profiles obtained after 6 and 24 hours of isotopic exposure at $360^{\circ} \mathrm{C}$ indicate that deuterium penetrates slowly beyond the previous profile in the layer. It means that the diffusion through the inner part of the oxide is likely the limiting step of the hydriding process.

The permeability of the outer part was confirmed by carrying out isotopic exposure at 200 and $300^{\circ} \mathrm{C}$ during just 1 hour in heavy water. The deuterium profiles obtained in these conditions are compared to that of the thermal transient (TT) sample in Figure 6.

\section{- Figure 6-}

Even at $200^{\circ} \mathrm{C}$, the deuterium penetration depth is already around $300-400 \mathrm{~nm}$. The profile at $300^{\circ} \mathrm{C}$ is relatively close to that obtained on the TT sample. These observations clearly show the high permeability for hydrogen of the external part of the oxide, even at low temperature. 
From these curves obtained at 200 and $300^{\circ} \mathrm{C}$, apparent diffusion coefficient of hydrogen in the outer part of the oxide can be evaluated as a function of temperature. The calculations will be detailed in the last part of this paper (cf. $\S 3.4 .1$ ).

\section{Post-transition stage}

As already mentioned, after the kinetic transition, the oxide film is more cracked and a high density of defects appears into the scale initially formed during the pre-transition stage. The hydrogen profile obtained on a Zy4 sample oxidized during 171 days of corrosion is presented on Figure 7. As for the pre-transition stage (Figure 3), we distinguish the external (1) and internal (3) layers. However, in the middle of the scale, a third layer is characterized by a relatively uniform concentration of hydrogen (2).

\section{-Figure 7-}

To know the characteristics of hydrogen transport in these scales, three experiments in heavy water were performed, one without isotherm plateau at $360^{\circ} \mathrm{C}(\mathrm{Z} 7$ TT sample in the figure 7), one with short exposure time $\left(\sim 6\right.$ hours at $\left.360^{\circ} \mathrm{C}\right)$ and another one with a much longer exposure time $\left(7\right.$ days at $\left.360^{\circ} \mathrm{C}\right)$. The deuterium profiles obtained are shown on Figure 8 .

\section{-Figure 8-}

The two external layers (1 and 2) are highly permeable to hydrogen and absorbed very quickly a relatively high quantity of deuterium. The diffusion profile of deuterium obtained on the TT sample actually shows a high penetration depth of this isotope down to the inner part of the oxide (3). This profile evidences that the outer part of the oxide formed during the pre-transition regime became permeable to hydrogen likely due to the microstructural 
degradation induced by the kinetic transition (of pores and cracks in this outer part of the oxide formed during the pre-transition regime.

However, the concentration gradient of deuterium in the inner part of the oxide and its progressive penetration as a function of isotopic exposure duration confirm that this part probably limits the deuterium diffusion towards the metal, as in the pre-transition regime. In other words, the hydrogen diffusion in the inner "protective" part of the oxide is the ratelimiting step of the hydrogen uptake process.

Since the concentration profiles observed in the inner sublayers for both oxides in pre- and post-transition regime looked very similar and showed that the global hydrogen/deuterium uptake process may be kinetically controlled by hydrogen transport in this very inner layer, supplementary experiments have been carried out.

In order to ensure sufficient diffusion time for deuterium to penetrate in this inner layer, 7day exposure to heavy water at $360^{\circ} \mathrm{C}$ were performed on specimen presenting oxides grown in both pre- and post-transition stages. The SIMS ${ }^{2} \mathrm{H}$-profiles were cut and replotted to show specifically the part involving the inner oxide. It allows for direct comparison between the two types of specimen as shown in Figure 9.

These profiles are superimposed showing that the deuterium gradients in the inner part of the oxide are similar in both cases.

\section{-Figure 9-}

The penetration depths are also similar. Assuming the hydrogen transport in the external layers is extremely quick compared to that in this inner layer, it suggests that the diffusion coefficient of hydrogen would be similar in the inner layer of the oxide, whatever the oxidation kinetic regime. 
Finally, these experiments clearly evidenced the difference of hydrogen mobility between the inner and the outer part of the oxide layers formed on $\mathrm{Zy} 4$ during the pre- and post-transition regimes. These results suggest that the interaction energies between hydrogen and the oxide are apparently not the same in the different sublayers.

\subsection{Interaction sites of hydrogen in oxide layers}

One must emphasize that it is much more accurate to work on deuterium than with hydrogen because the signal/noise ratio is much better for the heaviest isotope due to the low natural isotopic ratio, and diminishes consistently the background due to hydrogen species desorption form the metal bulk of the specimen and from all other surfaces present in the device. For this reason, the TDS spectra exposed next show specifically the deuterium desorption rate versus time or temperature.

\subsubsection{Identification of hydrogen interaction sites in the oxide layer}

The first series of thermal desorption analyses were carried out on samples corroded in PWR conditions up to $1.6 \mu \mathrm{m}$ oxide thickness and then exposed during 24 hours in heavy water at $360^{\circ} \mathrm{C}$. Figure 10 shows a typical thermal desorption spectrum. The deuterium desorption flux $\left({ }^{2} \mathrm{H}_{2}{ }^{+} ; \mathrm{m} / \mathrm{z}=4\right)$ is recorded as a function of time or temperature with a T ramp of $300 \mathrm{~K} / \mathrm{h}$. This spectrum exhibits two well defined desorption peaks, pointing at 740 and $840 \mathrm{~K}$, showing a presence of two populations of ${ }^{2} \mathrm{H}$ interaction sites with the specimen.

\section{-Figure 10-}


In addition, no signal of hydrogen is detected during the heat treatment desorption analysis (not presented here). It means that, after a $24 \mathrm{~h}$ isotopic exposure, hydrogen initially contained in the oxide layers has been replaced by deuterium. Deuterium being mainly localized in the oxide according to the SIMS profiles (cf. Figure $5 \mathrm{~b}$ ), desorption peaks are attributed to ${ }^{2} \mathrm{H}$ interactions within the oxide layer. These could be due to ${ }^{2} \mathrm{H}$ interaction with the lattice or ${ }^{2} \mathrm{H}$ trapping at specific sites or defects in the oxide (pores, vacancies...).

\subsubsection{Filling time of the sites}

The objective in this part is to follow the filling of the interaction sites function of the isotopic exposure time in order to qualitatively estimate the exchange kinetics of each site.

\section{-Figure 11-}

Figure 11 shows the TDS spectra obtained on the same samples as those in Figures $5 \mathrm{a}$ and $5 \mathrm{~b}$. The first and second kinds of interaction site desorbing, respectively, at $740 \mathrm{~K}$ and at $840 \mathrm{~K}$ (maximum) are, respectively, referred later to "type 1" and "type 2". The spectra evidence that almost all the type 1 sites are occupied even in the case of the TT sample since their occupancy does not vary for further exposure times. This is consistent with the SIMS concentration profiles described early in the paper. Besides, when the time of isotopic exposure increases, deuterium occupies progressively the second type of sites (type 2, associated with the desorption peak around $840 \mathrm{~K}$ ). Moreover, it is likely, by comparing the deuterium amount increase in the second interaction site with the deuterium penetration depth shown on Figure 5b, that these sites are located in the inner part of the oxide. This fact will be definitely validated in the next paragraph. 
In addition, the filling degree of the second type interaction versus time of isotopic exposure has been approximately estimated by integrating the peak corresponding to that site. Typically, their filling rates for the TT and 6-hours isotopic exchange samples compared with the one obtained after 24-hours isotopic exposure are, respectively, around $15-20 \%$ and 30 $35 \%$. It confims actually that the filling of the type 2 site is slow and progressive, as the deuterium diffusion in the inner part of the oxide.

\subsubsection{Location of hydrogen interaction sites}

To confirm the location of the different trapping sites for hydrogen (deuterium), we performed TDS experiments in order to desorb only deuterium that was located in the first type of interaction site. The associated thermal treatment consisted in an interrupted temperature ramp stopped at the temperature corresponding to the maximum desorption rate associated with the first peak $(740 \mathrm{~K})$ immediately followed by slow cooling of the specimen. Then SIMS analyses of the deuterium distribution have been carried out.

\section{-Figure 12-}

The deuterium SIMS profiles obtained after this thermal treatment are shown on Figure 12b. Assuming all deuterium associated with the first type of interaction sites was desorbed from the specimen during the heat treatment, and by comparison between the new deuterium concentration profile with the one before heat treatment, it becomes obvious that, as expected, the first type of interaction site is located close to the surface. Moreover, it seems that the 
second type of interaction sites (pointed by the remaining deuterium) are preferentially localised in the middle of the oxide layer, probably also close to the metal/oxide interface, although a small part is present close to the surface. Note that the deuterium concentration profile observed in fig $12 \mathrm{~b}$ results from the convolution of the interaction sites distribution and of the deuterium diffusion profile, hence not fully representative of the effective interaction site distribution.

In addition, the interaction site density, $\rho$, can be calculated by integration of each peak of each interaction site from TDS experiments considering that the sites after 24 hours of exposure are totally occupied. The proportion of the second type interaction sites corresponds to around $70 \%$ of all sites for a sample oxidized during 50 days. However, after thermal desorption of the type 1 sites, it remains only $27 \%$ of the initial integrated intensity of the SIMS profile which is much lower than the initial proportion of the type 2 site i.e. after isotopic exposure. It surely suggests that we partially desorbed the type 2 sites during the heating or that a deuterium diffusion process towards the metal occurred during the thermal treatment.

\subsubsection{Interaction sites of hydrogen in a post-transition oxide layer}

A TDS experiment was carried out on a Zy4 sample oxidized during 171 days in PWR simulated conditions and next exposed 6 hours in heavy water.

\section{- Figure 13 -}

The TDS spectrum obtained on a thick post-transition oxide reveals a huge desorption peak at around $800 \mathrm{~K}$ but the different deuterium interaction sites do not appear separately on the 
TDS spectrum (Figure 13). However, the slight shoulder at high temperature (840 K) on the thermogram could correspond to the deuterium desorption of the second type interaction sites mentioned previously.

Secondly, the huge peak probably describes the deuterium desorption from the first interaction sites evidenced in pre-transition. However, in this case, the maximum desorption rate should be between 720 and $750 \mathrm{~K}$ as in the pre-transition stage. Two assumptions can be suggested to explain this shift. The observed delay of the maximum desorption rate may be due to the diffusion of the great deuterium quantity coming from the first interaction site associated with the long way to cross the external oxide towards the surface. Another possibility is the existence of a third interaction site generated by the degradation of the scale during the kinetic transition and located in the zone (2) as indicated in Figure 7.

One can roughly estimate the deuterium amount trapped in the sites by integrating the thermograms obtained during the pre and the post-transition stages (cf. Table 4).

\section{-Table 4-}

As indicated in Table 4, the global hydrogen amount trapped in the sites of a post-transition oxide is at least 10 times higher than that obtained in pre-transition. The post-transition oxide layer absorbs a huge amount of hydrogen in the outer part of the scale. It may be due to the presence of pores and cracks induced by the kinetic transition.

\subsection{Diffusion coefficient of hydrogen in oxide layers}

\subsubsection{Diffusion coefficient in the outer part of the oxide}


Using the deuterium profiles obtained after exposure at $200^{\circ} \mathrm{C}$ and $300^{\circ} \mathrm{C}$ presented on Figure 6 , the diffusion coefficient in the outer part of the layer can be estimated by fitting the curves with the analytical solution of the Fick's second law given by the following formula (Eq. 4) :

$$
\frac{C(x)}{C_{\mathrm{s}}}=\left(1-\operatorname{erf}\left(\frac{x}{2 \sqrt{D t}}\right)\right)
$$

where $C_{\mathrm{s}}$ is the deuterium concentration at the surface $\left(\mathrm{mol} / \mathrm{cm}^{3}\right)$, supposed constant throughout the exposure to primary media, $C(x)$ the concentration at position $x\left(\mathrm{~mol} / \mathrm{cm}^{3}\right), D$ the apparent diffusion coefficient of hydrogen $\left(\mathrm{cm}^{2} / \mathrm{s}\right), t$ the isotopic exposure time $(\mathrm{s})$ and $x$ the oxide depth $(\mathrm{cm})$.

As illustrated in Figure 14 for the sample exposed one hour in heavy water at $200^{\circ} \mathrm{C}$, the fitted curve is almost superimposed on the experimental dots.

\section{- Figure 14-}

By applying the same fitting method to the concentration profile obtained after exposure at $300^{\circ} \mathrm{C}$ to the primary media, the diffusion coefficients of deuterium in the outer part of the oxide were estimated :

$\mathrm{D}\left({ }^{2} \mathrm{H}\right)_{200}{ }^{\circ} \mathrm{C}=5.1 \times 10^{-14} \mathrm{~cm}^{2} / \mathrm{s}$

$\mathrm{D}\left({ }^{2} \mathrm{H}\right)_{\left(300^{\circ} \mathrm{C}\right.}=2.24 \times 10^{-13} \mathrm{~cm}^{2} / \mathrm{s}$.

Considering that diffusion coefficient in the outer oxide follows an Arrhenius law, we deduce from the previous values its expression as a function of temperature (Eq. 5) :

$$
D(T)=2.5 \times 10^{-10} \operatorname{Exp}\left(-\frac{33430}{R T}\right) \quad\left(\mathrm{cm}^{2} / \mathrm{s}\right)
$$

The activation energy and the pre-exponential factor of the diffusion coefficient are, respectively, around $33 \mathrm{~kJ} \cdot \mathrm{mol}^{-1}$ and $2.5 \times 10^{-10} \mathrm{~cm}^{2} \mathrm{~s}^{-1}$. 
This diffusion coefficient of hydrogen in the outer part of oxides formed on Zy4 alloys was also estimated using modelling of deuterium diffusion through two sublayers by I. Takagi et $a l$. [41] and the values obtained by these authors are very close to that estimated during this work as shown on Figure 18 (cf.next section).

\subsubsection{Diffusion coefficient in the inner part of the oxide}

\section{Simulation with Cast $3 m$ code}

The estimation of a diffusion coefficient of hydrogen (deuterium) in the inner part of the oxide is not possible by using the same approach as developed in previous section, for many reasons: (i) the surface concentration (at the outer/inner oxide layer interface) cannot be assumed constant throughout the exposure duration, even if it is assumed that hydrogen diffuses quickly in the outer layer, which condition is somehow mandatory for the use of simple solutions of the Fick's second law, (ii) the hydrogen flux at this interface is not constant, at least in the first moments, leading to an evolving interface concentration, conditions discarding any possibility of analytical solution of Fick's second law, and (iii) the temperature is not constant during the whole experiment (typically 1 hour heating for 6 hours at isotherm). This observation leads us to use a numerical tool to code and simulate the diffusion of hydrogen in the inner part of the oxide, Cast $3 \mathrm{~m}$ in our case. Moreover, this code needs as input data some boundary conditions, such as the hydrogen concentration profile at the start of the isothermal conditions $\left(360^{\circ} \mathrm{C}\right)$. To this aim,

a specific autoclave with a rapid cooling system was used. Indeed, in usual autoclaves, the time of the isotherm plateau of 6 hours is similar to that of the thermal transient with a 1 -hour heating period and several hours of cooling. To limit the diffusion of deuterium during the 
cooling step, another experiment of 6-hours isotopic exposure was carried out in the fast water-cooled autoclave. The time of heating and cooling was about only 50 minutes (45 minutes for heating and less than 5 minutes for cooling down). Sample characteristics and heat treatments undergone are detailed in Table 5.

\section{- Table 5-}

The deuterium profile obtained after a 6-hours exposure time in ${ }^{2} \mathrm{H}_{2} \mathrm{O}$ of a pre-transition oxide (Z10 sample) as well as that of the TT sample (only thermal transient with no isothermal plateau at $360^{\circ} \mathrm{C}$, rapid-cooling autoclave) are presented in Figure 14. As already observed, SIMS analyses obtained on the TT sample show a significant penetration depth of deuterium during the thermal transient.

\section{-Figure 14-}

Due to the fact that the deuterium concentrations in the grain and in the grain boundaries are unknown after the thermal transient, we cannot numerically simulate with the finite elements Cast $3 \mathrm{~m}$ code the coupled diffusion process in the grain boundaries and in the bulk. Fick's second law (Eq. 6) was just applied to describe the one-dimensional transient diffusion process of hydrogen in the inner part of the oxide:

$$
\frac{\partial C}{\partial t}=D_{\mathrm{a}}\left[\frac{\partial^{2} C}{\partial x^{2}}\right]
$$


where $C$ is the deuterium concentration $\left(\mathrm{mol} / \mathrm{cm}^{3}\right)$ at position $x$ and time $t$ and $D_{\text {a }}$ the apparent diffusion coefficient in the inner oxide $\left(\mathrm{cm}^{2} / \mathrm{s}\right)$.

The initial boundary condition is given by the thermal transient profile of deuterium (TT sample) corresponding to the initial concentration profile at the start of the isothermal conditions.

This profile of deuterium used as initial conditions was actually simplified by a gradient with the same penetration depth (here $0.7 \mu \mathrm{m}$ from the interface) (black dotted line in Figure 15) with an interfacial concentration equal to $C s$. This concentration gradient was entered as boundary condition in the Finite Element Cast3m code. Fick's second law was then numerically solved to simulate the SIMS profile of deuterium in the inner part of the oxide during a 6-hours isotopic exposure time, assuming that $C s$ was constant throughout the whole isothermal treatment. Figure 15 shows the two normalized experimental SIMS concentration profiles, the initial concentration gradient used as input boundary condition, and two envelop simulations of the normalized concentration profile obtained after 6 hours of isothermal $\left(360^{\circ} \mathrm{C}\right)$ exposure to the media.

\section{-Figure 15-}

According to these numerical fits, the apparent diffusion coefficient of deuterium ranges between $2 \times 10^{-14} \mathrm{~cm}^{2} / \mathrm{s}$ and $5 \times 10^{-14} \mathrm{~cm}^{2} / \mathrm{s}$. This method of $D_{\mathrm{a}}$ determination is not very accurate, owing to the error induced by the very low penetration depth after 6 hours of isotopic exposure. However it gives an order of magnitude which is acceptable for diffusion coefficient evaluation.

Another approach was then implemented using in particular Elastic Recoil Detection Analysis technique in order to estimate this coefficient with another method. 
Indirect method using hydrogen quantification by Elastic Recoil Detection Analysis

Elastic Recoil Detection Analysis technique is able to quantify the average hydrogen amount in the oxide. The hydrogen SIMS profiles in the pre- and the post-transition oxide layers can then be quantified..

Figure 16 a) and $16 \mathrm{~b}$ ) present the principle of the ERDA technique and scanning electron micrograph of the post-transition sample (cross-section with a cutting angle of $10^{\circ}$ ). In Figure 16c, hydrogen cartography obtained with ERDA technique on post-transition oxide is coupled with the corresponding ERDA spectrum of the Region Of Interest (Figure 16d). The same analysis was carried out on the pre-transition sample (Z3). In the metal part (Figure 16c), some over-concentrated hydrogen zones are observed and reveal the presence of precipitated zirconium hydrides at ambient temperature.

\section{-Figure 16a-b}

\section{-Figure 16c-d-}

Thanks to this technique calibrated from the measurement of hydrogen signal in a standard polymer, the Kapton ${ }^{\circledR}$, average concentrations of hydrogen in the oxide are measured, typically, $8 \times 10^{20} \mathrm{at} / \mathrm{cm}^{3}$ for the oxide formed in the pre-transition stage and $1.1 \times 10^{21} \mathrm{at} / \mathrm{cm}^{3}$ in the post-transition stage corresponding to, respectively, $1.3 \times 10^{-3}$ and $1.8 \times 10^{-3} \mathrm{~mol} . \mathrm{cm}^{-3}$. The results are given in Table 6.

\section{-Table 6}


These values show that the hydrogen concentrations in the oxide layers are relatively high, around 1 at. $\%$ and slowly increases with oxidation time. They can be directly related to the integrated area below the SIMS profiles and thus used to quantify these profiles as illustrated in Figure 17. As indicated in Figure 17, the $C_{\mathrm{s}}$ concentration of hydrogen at the entrance of the inner part of the film can finally be deduced by this way. The $C_{\mathrm{s}}$ values are respectively $1.83 \times 10^{-3}$ mol. $\mathrm{cm}^{-3}$ and $2.16 \times 10^{-3}$ mol.cm ${ }^{-3}$ during the pre and the post-transition stages (cf. Table 6).

\section{- Figure 17-}

These results coupled with $\mathrm{H}$ amount measurements in the materials (cf. Table 3) are used to determine an apparent diffusion coefficient of hydrogen in the oxide film.

Considering that the hydrogen pickup kinetics is controlled by the hydrogen diffusion in the inner part of the oxide, the expression of the hydrogen flux, $J_{\mathrm{H}}$, absorbed by the alloy during the oxidation time (50 and 171 days) can be simply expressed, in steady state, as (Eq. 7):

$$
J_{\mathrm{H}}=D_{\mathrm{a}} \frac{\Delta C}{\Delta x}
$$

where $D_{\mathrm{a}}$ is the apparent diffusion coefficient of hydrogen in the inner part of the oxide layer $\left(\mathrm{cm}^{2} / \mathrm{s}\right), \Delta C$ is equal to the difference between the concentration of hydrogen at the entrance of the inner part of the film, $C_{\mathrm{s}}$, and the hydrogen content at the metal/oxide interface $C_{0}$ $\left(\mathrm{mol} . \mathrm{cm}^{-3}\right)$ and $\Delta x$ the thickness of the inner layer, which is accessed by the difference between the global oxide thickness $\left(X_{\mathrm{t}}\right)$ and that of the outer part of the oxide $\left(X_{\mathrm{o}}\right)(\mathrm{in} \mathrm{cm})$. The whole oxide thickness, $X_{\mathrm{t}}$, is described by the equation (Eq.1) and that of the outer part of the oxide $\left(X_{\mathrm{o}}\right)$ is taken to $0.3 \mu \mathrm{m}\left(0.3 \times 10^{-4} \mathrm{~cm}\right)$ as mentioned earlier.

The hydrogen concentration at the metal/oxide interface, $C_{0}$, is taken to be the fifth of the $C s$ value (cf. Figure 4b). 
The hydrogen amount, $n_{\mathrm{H}}^{\mathrm{Zr}}$ (in mol.cm ${ }^{-2}$ ), absorbed by the alloy during the corrosion process is given by the integration of the flux during the exposure time and is written in the pretransition stage, as (Eq. 8):

$n_{\mathrm{H}}^{\mathrm{Zr}}=\frac{4}{5} D_{\mathrm{a}} C_{\mathrm{s}}\left[\frac{86400}{10^{-4}} \int_{\varepsilon}^{50} \frac{\mathrm{d} t}{0.47 t^{0.3}-0.3}\right]$

where $\varepsilon$ is taken to be equal to 0.5 day in order to get a definite integral. The term in brackets, $\frac{86400}{10^{-4}} \int_{\varepsilon}^{50} \frac{\mathrm{d} t}{0.47 t^{0.3}-0.3}$, is homogeneous to $\mathrm{s} / \mathrm{cm}$

The hydrogen amount, $n_{\mathrm{H}}^{\mathrm{Zr}}\left(\right.$ in $\left.\mathrm{mol} . \mathrm{cm}^{-2}\right)$, corresponding to the hydrogen content absorbed in the metallic part of the alloy during the oxidation (per unit area) can be deduced from the measurements obtainedby fusion giving the whole hydrogen amount absorbed by the material per unit area, $n_{\mathrm{H}_{-} \text {fusion }}^{\mathrm{Zr} \mathrm{Zr}_{2}}\left(\right.$ in mol.cm ${ }^{-2}$ ), and fromthe ERDA results giving the hydrogen amount in the oxide, $n_{\mathrm{H} \_ \text {ERDA }}^{\mathrm{ZrO} 2}\left(\right.$ in mol.cm-2 ${ }^{-2}$. It is expressed by the following formula (Eq. 9):

$n_{\mathrm{H}}^{\mathrm{Zr}}=n_{\mathrm{H}-\text { fusion }}^{\mathrm{Zr}+\mathrm{ZrO}_{2}}-n_{\mathrm{H}-\mathrm{ERDA}}^{\mathrm{ZrO}_{2}}$

However, we have to emphasize that the concentrations of hydrogen, $C_{\mathrm{H}_{-} \text {fusion }}^{\mathrm{Zr} \mathrm{ZrO}_{2}}, C_{\mathrm{H}_{-} \mathrm{ERDA}}^{\mathrm{ZrO}}$ given in Tables 3 and 6 have to be multiplied by the half thickness of the metal and the thickness of the oxide layer to get the hydrogen matter amount per unit area.

$n_{\mathrm{H}}^{\mathrm{Zr}}$ and $C s$ are experimentally known and $\frac{86400}{10^{-4}} \int_{0.5}^{50} \frac{\mathrm{d} t}{0.47 t^{0.3}-0.3}$ is evaluated by integration. The apparent diffusion coefficient is then deduced from the equation (Eq. 8). Its value is given in Table 7.

In the post-transition region, the two corrosion cycles have to be taken into account. More specifically, the total hydrogen absorption is the sum of the integrated fluxes, for the first 
cycle, from $\varepsilon$ until the kinetic transition (125 days to reach $2 \mu \mathrm{m}$ ) and, for the second cycle, from $\varepsilon$ until the end of the corrosion duration (last 46 days, from 125 days until the 171 days of corrosion). The hydrogen amount in the metal is expressed as (Eq. 10) in post-transition:

$n_{\mathrm{H}}^{\mathrm{Zr}}=\frac{4}{5} D_{\mathrm{a}} \cdot C_{\mathrm{s}} \cdot\left(\frac{86400}{10^{-4}} \int_{\varepsilon}^{125} \frac{\mathrm{d} t}{0.47 t^{0.3}-0.3}+\int_{\varepsilon}^{46} \frac{\mathrm{d} t}{0.47 t^{0.3}-0.3}\right)$

The equation (Eq. 9) is unchanged for the post-transition regime and the method is the same as previously.

Finally, the calculated values of the apparent diffusion coefficients obtained by this way of determination are compared to those obtained with the Cast $3 \mathrm{~m}$ code in Table 7.

-Table 7-

As indicated in this table, the apparent diffusion coefficients of hydrogen deduced from the ERDA results in the pre-transition and in the post-transition oxides are in good agreement with the rough estimation based on the Cast $3 \mathrm{~m}$ code. These values are similar and support the hypothesis of an identical apparent diffusion coefficient of hydrogen in the oxide formed during the pre- and the post -transition stages in the inner oxide layer.

Finally, the apparent diffusion coefficient of hydrogen in oxides grown on Zircaloy-4 is around $2.10^{-14} \mathrm{~cm}^{2} / \mathrm{s}$ at $360^{\circ} \mathrm{C}$. This value is close to those evaluated by Khatamian $[19,20$, 38, 39] or Tagaki et al.[41] as shown on Figure 18. First of all, as usually observed, the values of hydrogen diffusion coefficient in zirconia are relatively dispersed and these of Khatamian and Tagaki are not very consistent in terms of migration enthalpy whereas the Zy2 alloy (red cross on Figure 18) and GNF-Ziron (blue empty squares on Figure 18) are similar in terms of chemical composition. 
Our values of diffusion coefficient in the inner part of the oxide are in good agreement with the values of Khatamian et al. because hydrogen during Khatamian's experiment is implanted in the inner part of the oxide. These authors followed then the diffusion of hydrogen through the inner sublayer after thermal treatment with Nuclear Reaction Analysis or SIMS. We carried out a similar experimental protocol as I. Takagi et al. [41] which performed numerical calculations considering hydrogen diffusion through two sublayers. We found similar hydrogen diffusion coefficient in the external part of the oxide while the data treatment was relatively different between these two studies.

\section{-Figure 18-}

\section{Conclusions}

The hydrogen distribution and diffusion in the oxide films formed during corrosion of Zircaloy-4 in primary water were studied in order to better understand the hydrogen uptake mechanism of the fuel cladding. The results of these investigations are the following:

1. The isotopic exposure campaign revealed that the pre-transition oxide was divided into two sub-layers: the external one, around $300 \mathrm{~nm}$-thick, is extremely permeable to hydrogen even at low temperature $\left(<300^{\circ} \mathrm{C}\right)$. Hydrogen diffuses much more slowly in the inner part of the oxide layer. Consequently it was assumed that the limiting step of the hydriding rate is the diffusion of hydrogen through this part of the oxide.

2. The post-transition oxide also presents the two same sub-layers (external and internal) but also an intermediate one in the middle of the scale. This latter is also permeable to hydrogen due to the presence of pores and cracks formed during the kinetic transition. The deuterium diffusion gradients in the inner 
part are the same in pre- and post-transition. This result tends to prove that the hydrogen pick-up mechanism is similar during these stages.

3. It was highlighted the presence of two interaction sites of hydrogen in oxide. Using various isotopic exposure times, we showed that the sites of the type 1 fill in first and this process occurs at relatively low temperature. The first interaction sites are mainly concentrated close to the surface whereas the second interaction sites are located in the bulk oxide and mainly in the inner part. The hydrogen diffusion through the second interaction sites towards the metal could limit the hydrogen uptake by the material. Beyond the kinetic transition, the deuterium amount trapped in the oxide layer strongly increases by at least a factor 10 due to the presence of pores and cracks in the layer formed during the pre-transition stage.

4. The Cast $3 \mathrm{~m}$ code allowed to roughly simulate the deuterium SIMS profile and to approximately estimate an apparent diffusion coefficient of hydrogen in the range between $2.10^{-14}$ and $5.10^{-14} \mathrm{~cm}^{2} / \mathrm{s}$ at $360^{\circ} \mathrm{C}$.

5. ERDA analyses of the oxide scales grown on Zircaloy-4 samples revealed a slightly higher content of hydrogen in the post-transition oxide compared with the pre-transition oxide, typically, $7.8 \times 10^{-5} \mathrm{~mol}_{\mathrm{cm}} \mathrm{cm}^{-3}$ in this latter and $2.0 \times 10^{-4} \mathrm{~mol} \mathrm{~cm}^{3}$ in the former so 1 and 1.3 at. \% respectively.

6. Thanks to the coupled ERDA and fusion measurements, calculations based on the diffusion flux of hydrogen during the corrosion process lead to similar values of $\mathrm{D}_{\mathrm{a}}$ in both types of oxides. This apparent diffusion coefficient is around $1.5 \times 10^{-14} \mathrm{~cm}^{2} / \mathrm{s}$, which is consistent with Cast $3 \mathrm{~m}$ simulations and literature data. 


\section{Acknowledgments}

The authors want to thank AREVA NP for material supplying and M. Blat from EDF for hydrogen fusion measurements and their financial support.

\section{$\underline{\text { References }}$}

[1] G.L. Garner, B.A. Hilton and E. Mader, "Performance of alloy M5 ${ }^{\mathrm{TM}}$ cladding and structure", LWR Fuel Performance Meeting/Top Fuel, San Francisco, 30 ${ }^{\text {th }}$ septembre- $3^{\text {rd }}$ October, 2007

[2] F. Garzarolli, H. Stehle, and E. Steinberg, "Behavior and Properties of Zircaloys in Power Reactors: A Short Review of Pertinent Aspects in LWR Fuel", in: Zirconium in the Nuclear Industry: Eleventh International Symposium, ASTM STP 1295 (1996) 12-32

[3] P. Bossis, B. Verhaeghe, S. Doriot, D. Gilbon, V. Chabretou, A. Dalmais, J.-P; Mardon M. Blat and A. Miquet, "In PWR Comprehensive Study of High Burn-Up Corrosion and Growth Behavior of M5 and Recrystallized Low-Tin Zircaloy-4", in: Zirconium in the Nuclear Industry: $15^{\text {th }}$ International Symposium, ASTM STP 1505 (2008) 430-456

[4] A.M. Garde, A. R. Pati, M. A. Krammen, G. P. Smith, G. P. and R. K. Endter, "Corrosion Behavior of Zircaloy-4 Cladding with Varying Tin Content in High-Temperature Pressurized Water Reactors", in: Zirconium in the Nuclear Industry: Tenth International Symposium, ASTM STP 1245 (1994) 760-778

[5] X. Iltis, F. Lefebvre and C. Lemaignan, "Microstructure Evolutions and Iron Redistribution in Zircaloy Oxide Layers: Comparative Effects of Neutron Irradiation Flux and Irradiation Damages", in: Zirconium in the Nuclear Industry: Eleventh International Symposium, ASTM STP 1295 (1996) 242-264

[6] P. Barberis, E. Ahlberg, N. Simic, D. Charquet, C. Lemaignan, G. Wikmark, M. Dahlbäck, M. Limbäck, P. Tägtström, and B. Lehtinen, "Role of the Second-Phase Particles in Zirconium Binary Alloys", in: Zirconium in the Nuclear Industry: Thirteenth International Symposium, ASTM STP 1423 (2002) 33-58

[7] D. Gilbon, "Les matériaux de gaines et d'assemblage" Les combustibles Nucléaires, monographie de la DEN, Edition du Moniteur, Paris, 2008, p. 38

[8] M. Tupin, J. Hamann, D. Cuisinier, P. Bossis, M. Blat, A. Ambard, A. Miquet, D. Kaczorowski, "Understanding of corrosion mechanisms of zirconium alloys after irradiation: effect of ion irradiation of the oxide layers on the corrosion rate", in : Zirconium in the Nuclear Industry, 17th International Symposium, ASTM STP 1543 (2014), pp. 438-478

[9] R. Verlet, M. Tupin, G. Baldacchino, K. Wolski, S. Miro, D. Gosset, K. Colas, M. Jublot, and F. Jomard, Corros. Sci. 98 (2015) 327-333 
[10] V. Bouineau, A. Ambard, G. Bénier, D. Pêcheur, J. Godlewski, L. Fayette, and T. Duverneix, "A new model to predict the oxidation kinetics of zirconium alloys in a Pressurized Water Reactor", in: Zirconium in the nuclear industry: $15^{\text {th }}$ International Symposium, ASTM STP 1505 (2008) 405-429

[11] A.M. Garde, "Enhancement of Aqueous Corrosion of Zircaloy-4 Due to Hydride Precipitation at the MetalOxide Interface", in: Zirconium in the Nuclear Industry: Ninth International Symposium, ASTM STP 1132 (1991) 566-594

[12] T. Kido, "A study on enhanced uniform corrosion of Zircaloy-4 cladding during high burnup operation in PWR's", in: Sixth International Symposium on Environmental Degradation of Materials in Nuclear Power Systems (1993) 449-455

[13] M. Blat and D. Noel, "Detrimental Role of Hydrogen on the Corrosion Rate of Zirconium Alloys", in: Zirconium in the Nuclear Industry: Eleventh International Symposium, ASTM STP 1295 (1996) 319-337.

[14] M. Blat, L. Legras, D. Noel and H. Amanrich, "Contribution to a Better Understanding of the Detrimental Role of Hydrogen on the Corrosion Rate of Zircaloy-4 Cladding Materials", in: Zirconium in the Nuclear Industry: Twelfth International Symposium, ASTM STP 1354 (2000) 563-591

[15] Y.S. Kim, K. S., Rheem and D. K. Min, "Phenomenological Study of In-Reactor Corrosion of Zircaloy-4 in Pressurized Water Reactors", in: Zirconium in the Nuclear Industry: Tenth International Symposium, ASTM STP 1245 (1994) 745-759

[16] Y. S. Kim, H. K. Woo, K. S., Im and S. L. Kwun, "The Cause for Enhanced Corrosion of Zirconium Alloys by Hydrides", in: Zirconium in the Nuclear Industry: Thirteenth International Symposium, ASTM STP 1423 (2002) 247-296

[17] M. Tupin, C. Bisor, P. Bossis, J. Chêne, J. L. Bechade, and F. Jomard, Corros. Sci. 98 (2015) 478-493

[18] L. Aufore, "Etude du transport de l'hydrogène produit lors de la corrosion des gaines d'éléments combustibles des réacteurs à eau sous pression dans la zircone et le Zircaloy-4”, in: PhD Thesis, Aix-Marseille 2 University (1997)

[19] D. Khatamian and F. D. Manchester , J. Nucl. Mater. 166 (1989) 300-306

[20] D. Khatamian, J. Alloys Compd. 253-254 (1997) 471-474

[21] B. Cox, J. Nucl. Mater. 264 (1999) 283-294

[22] E. Hillner, "Hydrogen absorption in Zircaloy during aqueous corrosion, effect of environment", in: U.S Report, WAPD-TM-411 (1964)

[23] C. Raepsaet, P. Bossis, D. Hamon, J.-L. Béchade and J.-C. Brachet, Nucl. Instr. Meth. B 266 (2008) $2424-$ 2428

[24] C. Wagner, "Beitrag zur Theorie des Anlaufvorgangs“, in: Z. Phys. Chem. B21 (1933) 25-41

[25] Y. Dali, M. Tupin, P. Bossis, M. Pijolat, Y. Wouters, F. Jomard, J. Nucl. Mater. 426 (2012) 148-159.

[26] A. Couet, T. Motta, Robert J. Comstock, J. Nucl. Mater. 451 (2014) 1-13

[27] J.S. Bryner, J. Nucl. Mater. 82 (1979) 84-101

[28] M. Parise, O. Sicardy and G. Cailletaud, J. Nucl. Mater. 256 (1998) 35-46

[29] B. Cox, J. Nucl. Mater. 29 (1969) 50-66

[30] F. Garzarolli, H. Seidel, R. Tricot and J. P. Gros, "Oxide Growth Mechanism on Zirconium Alloys", in: Zirconium in the Nuclear Industry: Ninth International Symposium, ASTM STP 1132 (1991) 395-415. 
[31] G. P. Sabol, S. G. MacDonald and G. P. Airey, "Microstructure of the Oxide Films Formed on ZirconiumBased Alloys", in: Zirconium in Nuclear Applications, ASTM STP 551 (1974) 435-447

[32] International Atomic Energy Agency, "Waterside corrosion of zirconium alloys in nuclear power plants", IAEA, VIENNA, 1998, IAEA-TECDOC-996, ISSN 1011-4289

[33] B. Kammenzind, D. G. Franklin, H. R. Peters and W. J. Duffin, "Hydrogen pickup and redistribution in alpha-annealed Zircaloy-4", in :Zirconium in the Nuclear Industry : 11th International Symposium, ASTM STP 1295 (1996) 338-370

[34] A. Yilmazbayhan, E. Breval A. T. Motta and R. J. Comstock, J. Nucl. Mater. 349 (2006) 265-281

[35] A. T. Motta, A. Yilmazbayhan, R. J. Comstock, J., Partezana, G. P. Sabol, B. Lai and Z. Cai, "Microstructure and Growth Mechanism of Oxide Layers Formed on Zr Alloys Studied with Micro-Beam Synchrotron Radiation", in: Zirconium in the Nuclear Industry: Fourteenth International Symposium, ASTM STP 1467 (2005) 205-233

[36] Anada, H., Herb, B. J., Nomoto, K., Hagi, S., Graham, R. A., and Kuroda, T., "Effect of Annealing Temperature on Corrosion Behavior and $\mathrm{ZrO}_{2}$ Microstructure of Zircaloy-4 Cladding Tube", in: Zirconium in the Nuclear Industry: Eleventh International Symposium, ASTM STP 1295 (1996) 74-93

[37] J.J. Kearns, J. Nucl. Mater. 22 (1967) 292-303

[38] D. Khatamian, Defect and Diffusion Forum 297-301 (2010) 631

[39] D. Khatamanian, Z. Phys. Chem. B181 (1993) 435-440

[40] Y. Hatano, R. Hitaka, M. Sugisaki and M. Hayashi, J. Radioanal. Nucl. Chem. 239 (1999) 445-448

[41] I. Takagi, K. Une, S. Miyamura, and T. Kobayashi, J. Nucl. Mater. 419 (2011) 339-346 


\section{Figure Captions :}

Figure 1 : Corrosion kinetics of Zircaloy- 4 samples during corrosion in primary water at $360^{\circ} \mathrm{C}$ and 18.7 $\mathrm{MPa}$. The black line is the fit with (Eq. 1) in pre and post-transition regimes. The kinetic transition appears around $2 \mu \mathrm{m}$ after 125 days of corrosion.

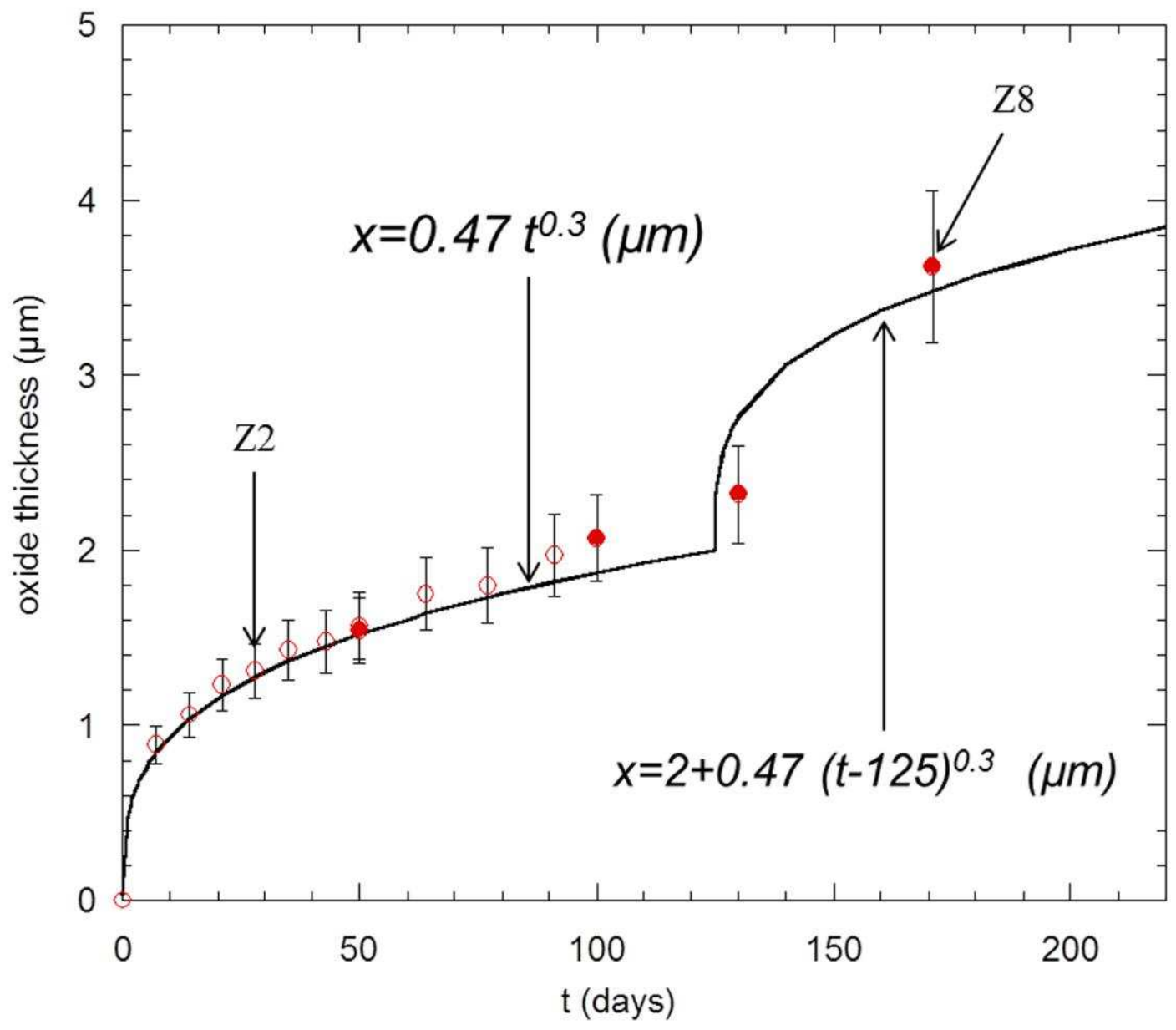


Figure 2 : Scanning electron micrographs of the fractured oxide scales formed on Zircaloy-4 samples during corrosion in the pre transition ( $a$ and b) or in the post transition ( $c$ and d) regime in primary water at $360^{\circ} \mathrm{C}$ and $18.7 \mathrm{MPa}$.
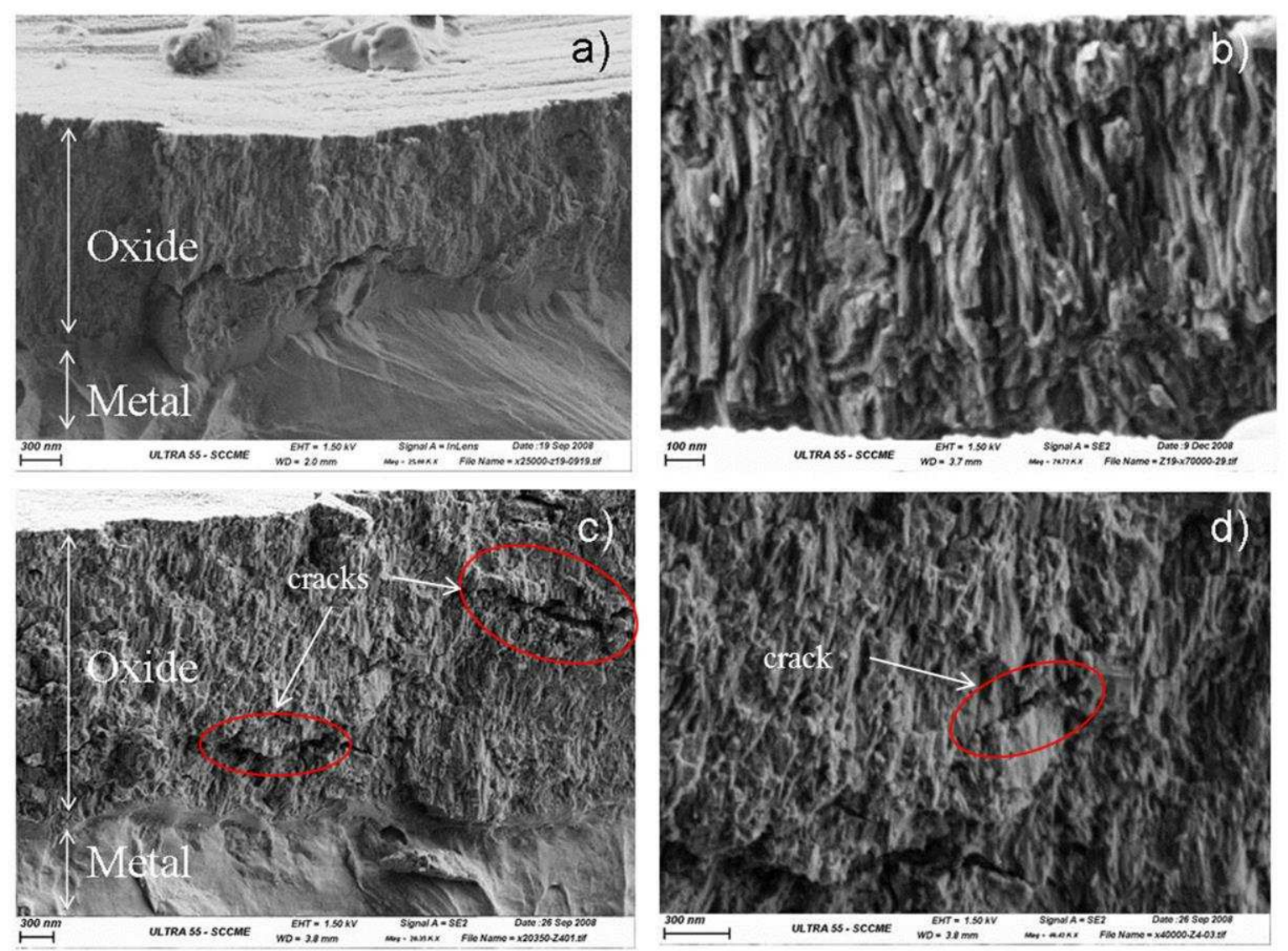
Figure 3 : SIMS profiles of hydrogen and oxygen obtained after a 50 day-corrosion in PWR conditions of a Zircaloy-4 sample (pre-transition regime).Insert : $\mathrm{H}$ ionic image of the crater after the SIMS analysis. Bright zones correspond to the high level contents of hydrogen in the metallic part of the alloy.

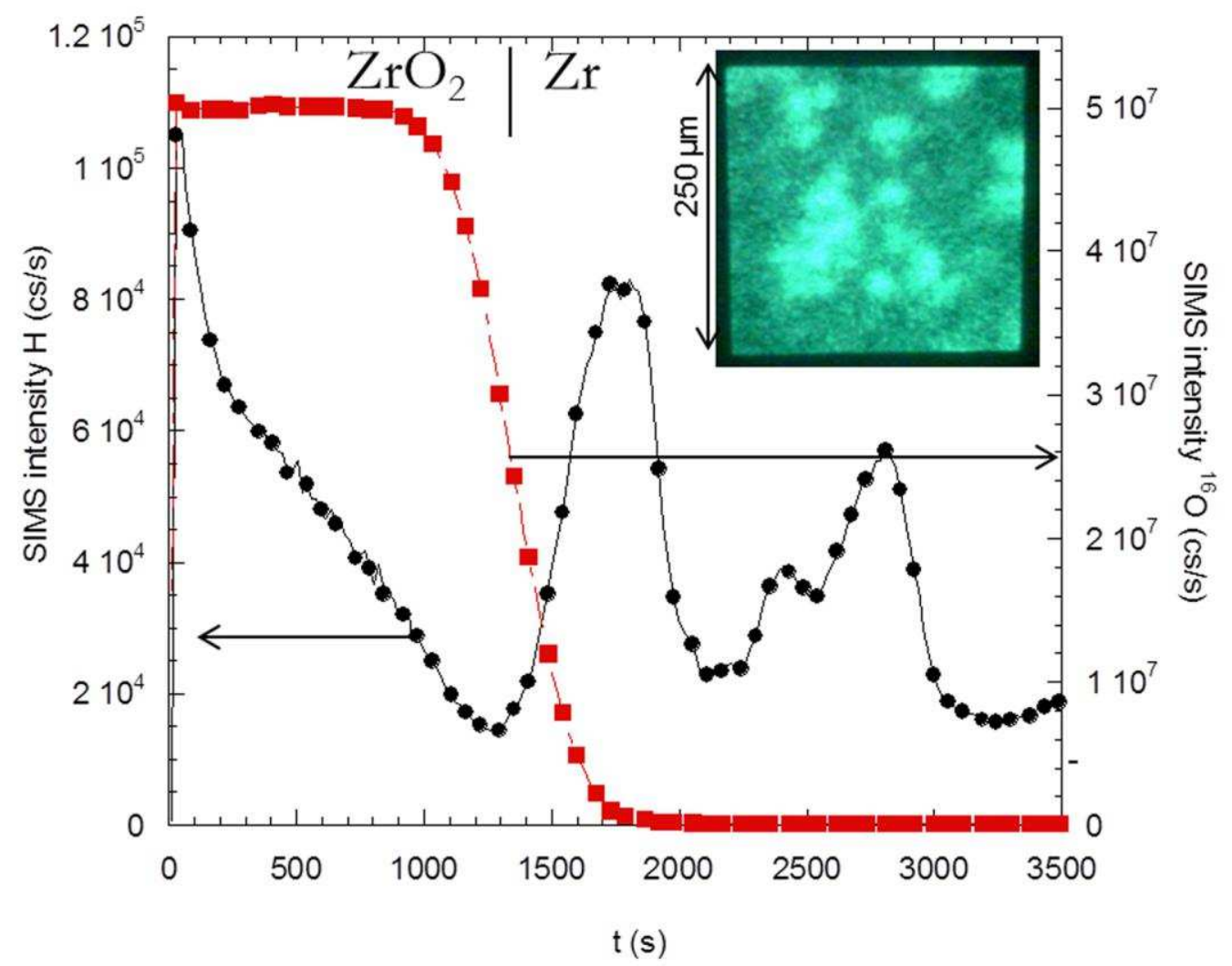


Figure $4:$ a) ${ }^{16} \mathrm{O}$ corrected profile (red squares) to get $5 \times 10^{7} \mathrm{cs} / \mathrm{s}$ on ${ }^{16} \mathrm{O}$ intensity. The vertical bar indicates the metal/oxide interface. b) $\mathrm{H}$ profile as a function of the oxide depth. The vertical bar separates the two sublayers.
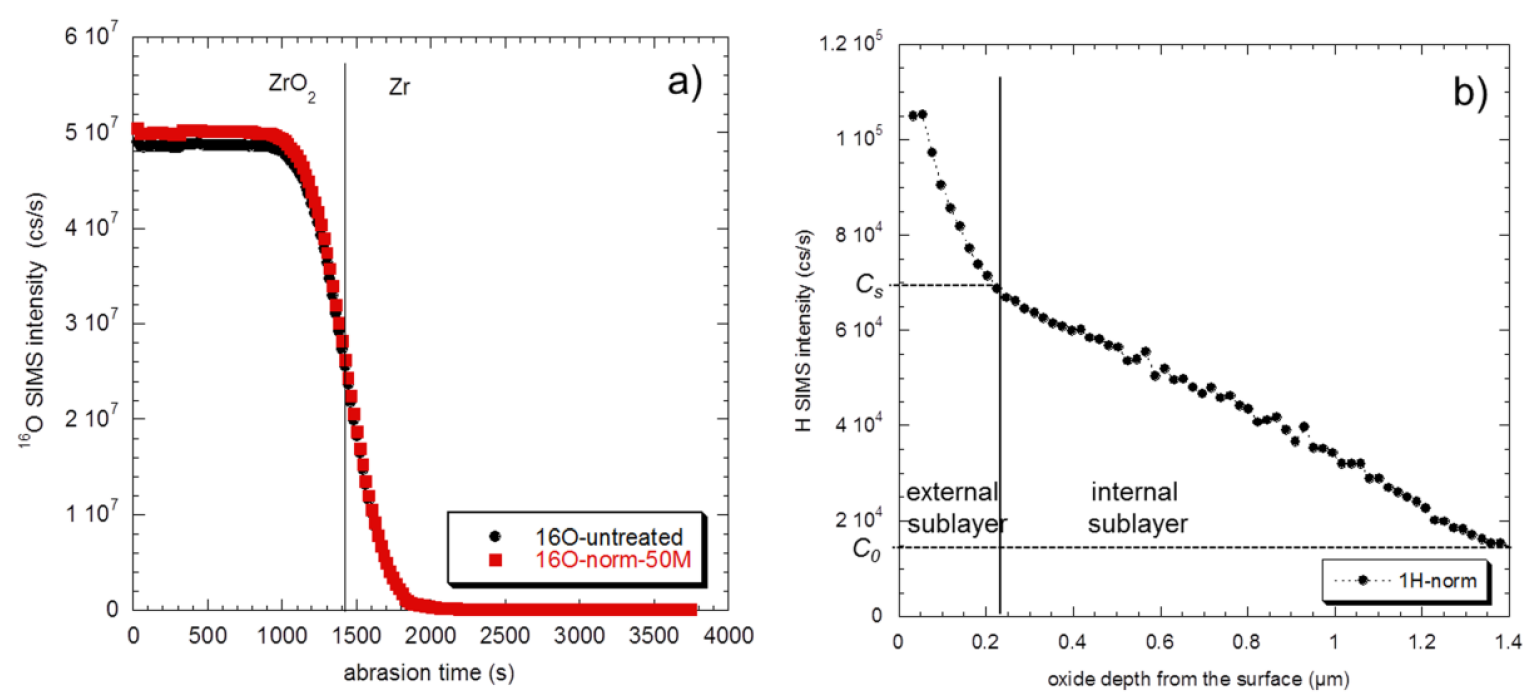
Figure $5:$ a) Schematic description of the thermal treatments undergone by the samples during isotopic exposure b) Deuterium SIMS profiles obtained on these samples - circles correspond to a heating step up to $360^{\circ} \mathrm{C}$ followed by a cooling step (ZD_TT sample) - squares to a 6 hours isotopic exchange at $360^{\circ} \mathrm{C}\left(\mathrm{Z} 4 \_6 \mathrm{~h}\right.$ sample $)$ - triangles to a 24 hours isotopic exchange at $360^{\circ} \mathrm{C}\left(\mathrm{ZD} \_24 \mathrm{~h}\right.$ sample).
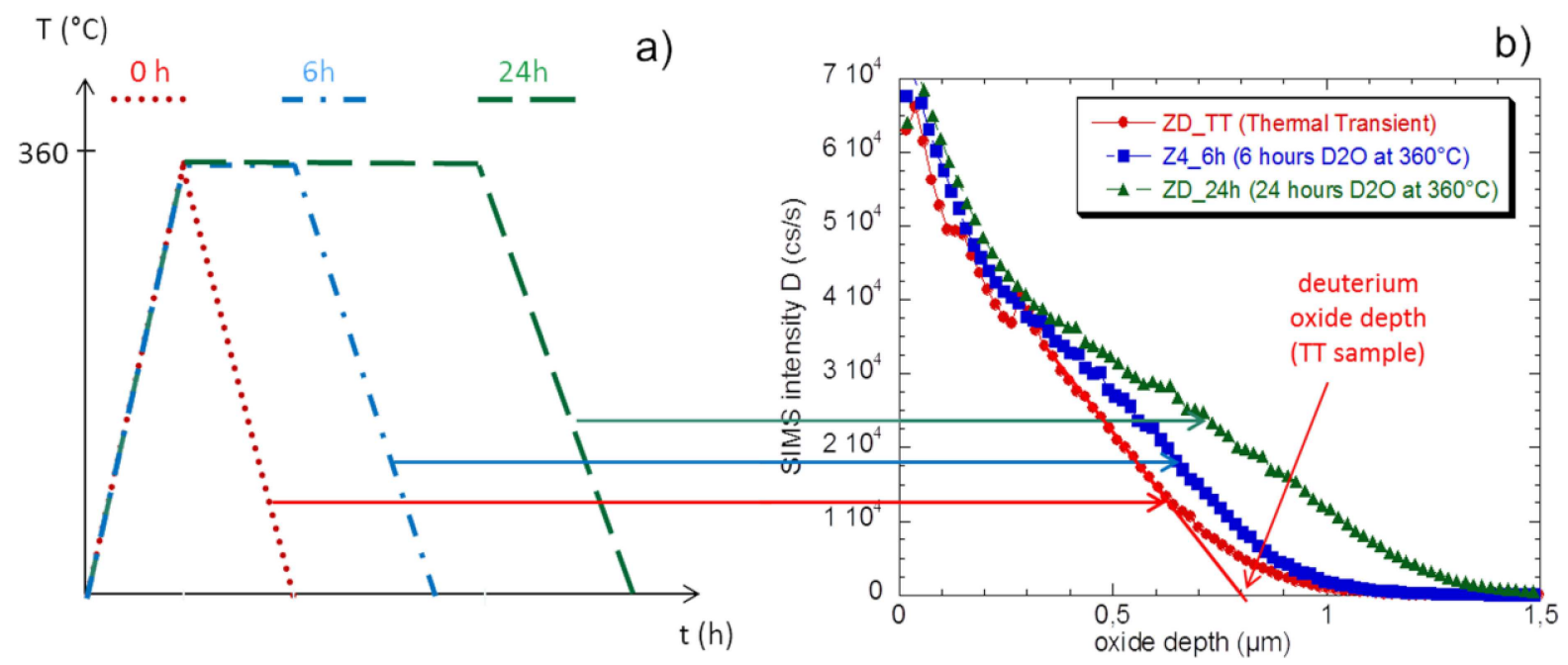
Figure 6 : a) Deuterium SIMS profiles obtained after 1 hour of isotopic exposure at low temperature, $200^{\circ} \mathrm{C}$ (dark square), $300^{\circ} \mathrm{C}$ (blue diamonds) and compared with that of the TT sample (red circles, ZD_TT sample). b) Fit (red continuous line) with (Eq. 3) of the deuterium SIMS profile obtained after 1 hour of isotopic exposure at $200^{\circ} \mathrm{C}$.

a)

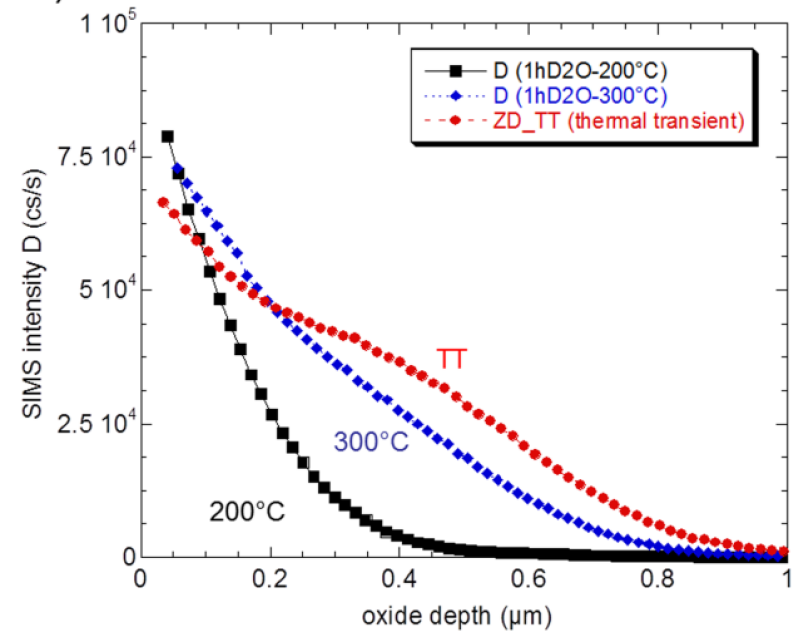

b)

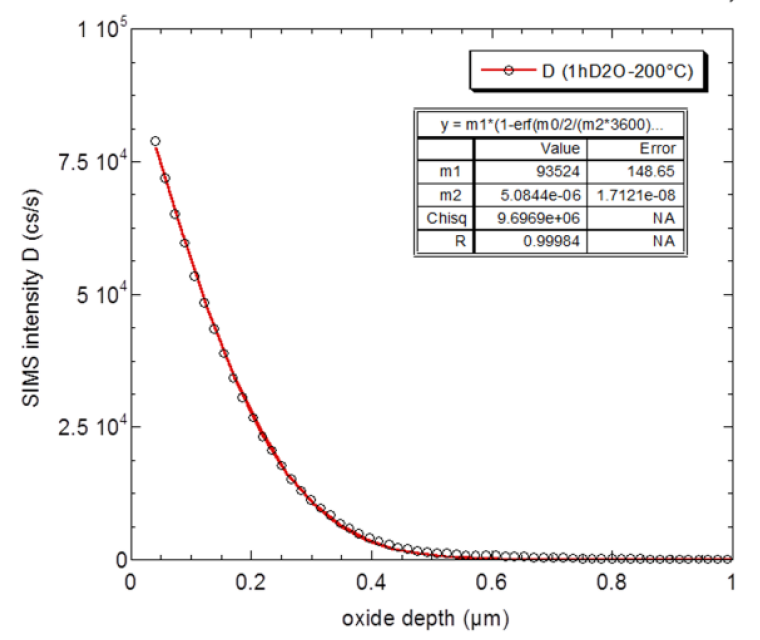


Figure 7 : SIMS profiles of hydrogen and oxygen obtained after a 171-days corrosion in PWR conditions of a Zircaloy-4 sample in the post-transition stage.

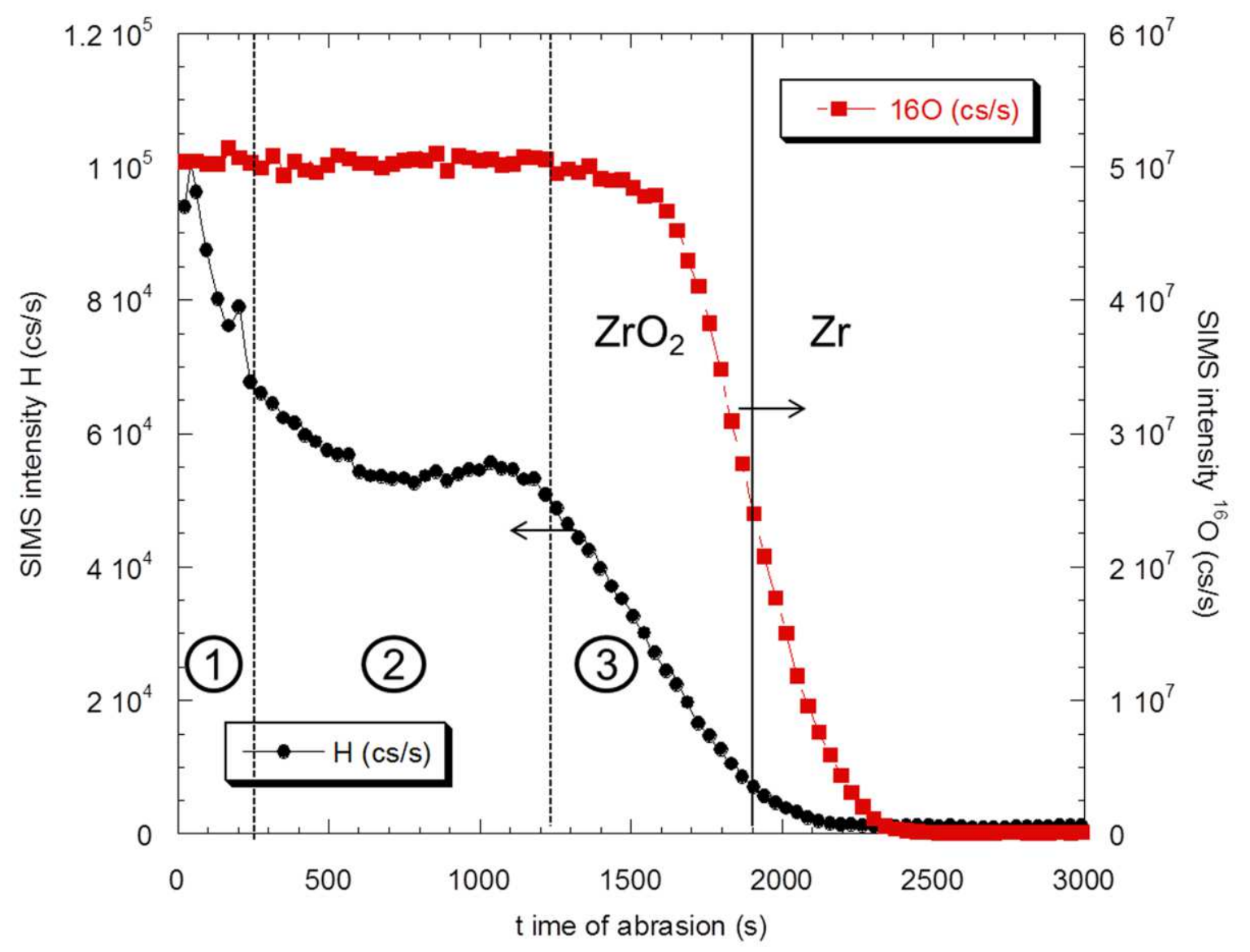


Figure 8 : Deuterium SIMS profiles obtained after a thermal transient (Z7_TT sample), 6 hours (Z7_6h sample) and 7 days (Z8 sample) of isotopic exposure in heavy water on Zircaloy-4 samples pre-corroded in the post-transition stage. X-axis extends until the $\mathrm{M} / \mathrm{O}$ interface after 7 days of reoxidation. The dotted line shows the beginning of the inner layer.

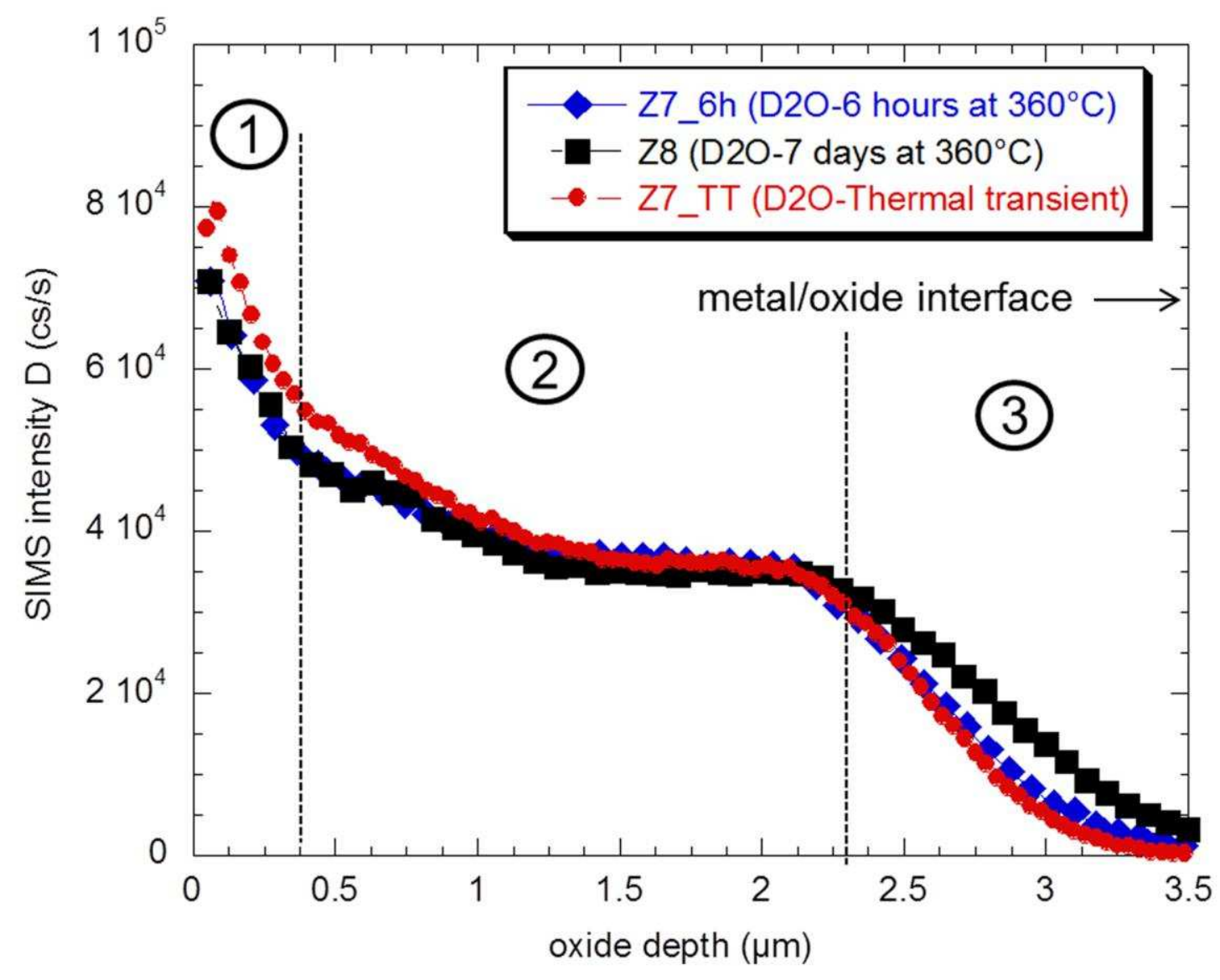


Figure 9: Superposition of deuterium profiles in the inner part of the oxides obtained after 7 days of re-oxidation in $\mathrm{D}_{2} \mathrm{O}$ in the case of pre-transition ( $(0)$ and post-transition ( $\square$ ) oxides.

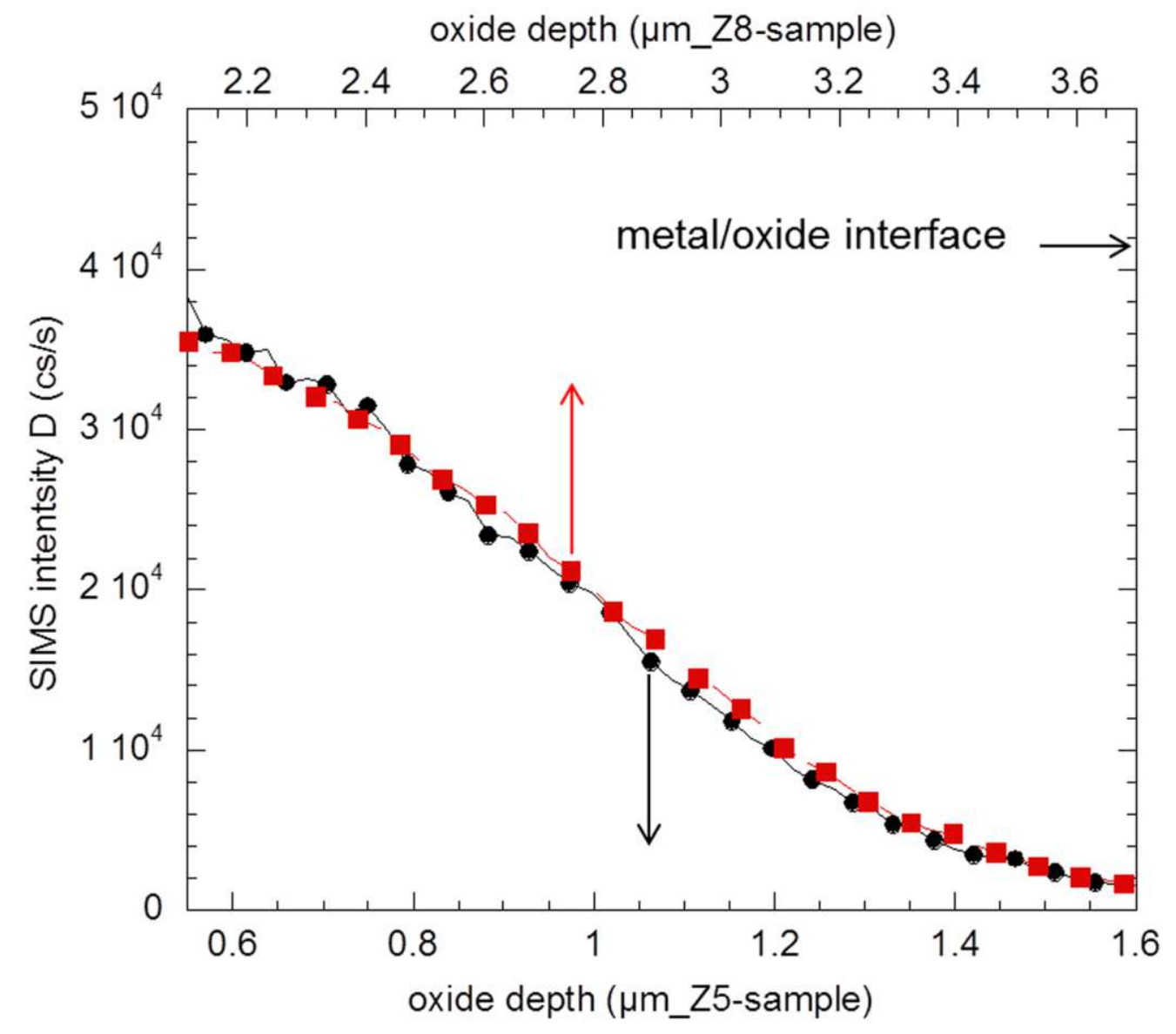


Figure 10 : Deuterium thermal desorption spectrum performed at $300 \mathrm{~K} / \mathrm{h}$ on a sample of zircaloy-4 oxidized during 50 days in $\mathrm{H}_{2} \mathrm{O}$ and exposed 24 hours in ${ }^{2} \mathrm{H}_{2} \mathrm{O}$ (ZD_24h sample).

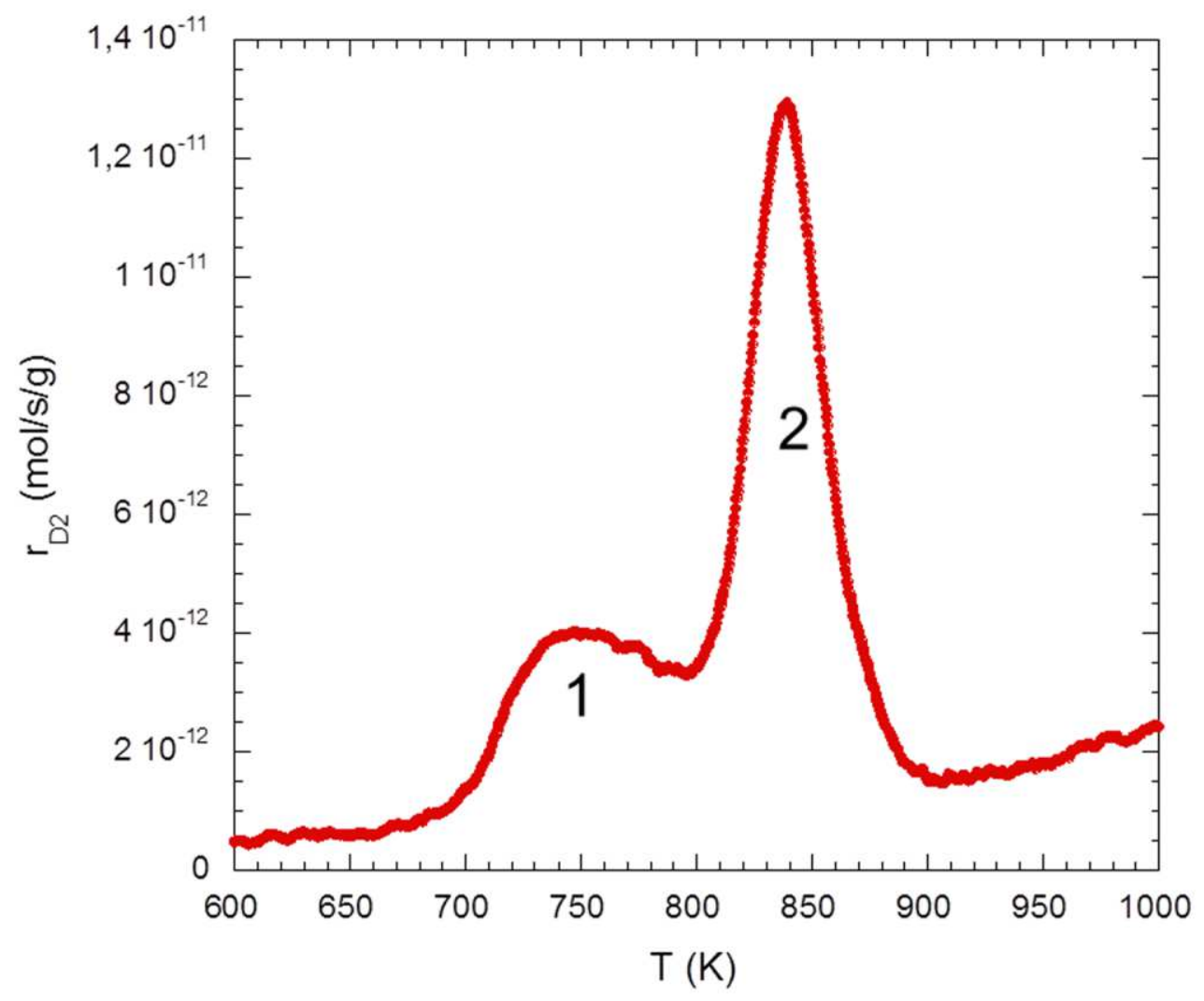


Figure 11 : Deuterium thermal desorption spectra performed on a sample of zircaloy-4 oxidized during 50 days in $\mathrm{H}_{2} \mathrm{O}$ and then submitted to a thermal transient in ${ }^{2} \mathrm{H}_{2} \mathrm{O}$ (dark squares), or exposed 6 hours in ${ }^{2} \mathrm{H}_{2} \mathrm{O}$ (blue diamonds) or 24 hours in ${ }^{2} \mathrm{H}_{2} \mathrm{O}$ (red circles), at $360^{\circ} \mathrm{C}$.

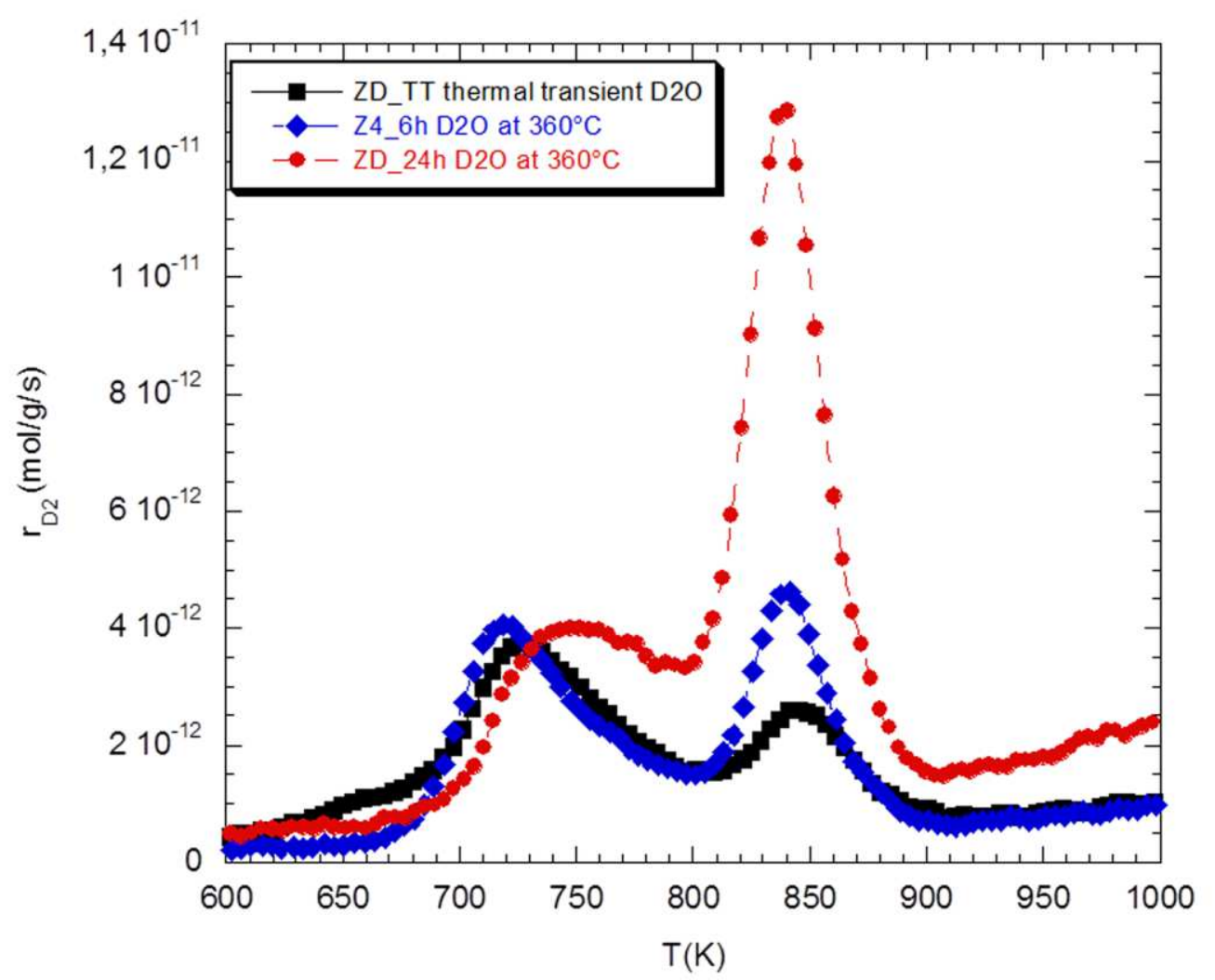


Figure 12 : Deuterium SIMS profiles of zircaloy-4 samples oxidized in light water during 50 days and exposed during 24 hours in ${ }^{2} \mathrm{H}_{2} \mathrm{O}$ before (red circles) and after (blue squares) deuterium desorption of the first interaction sites.

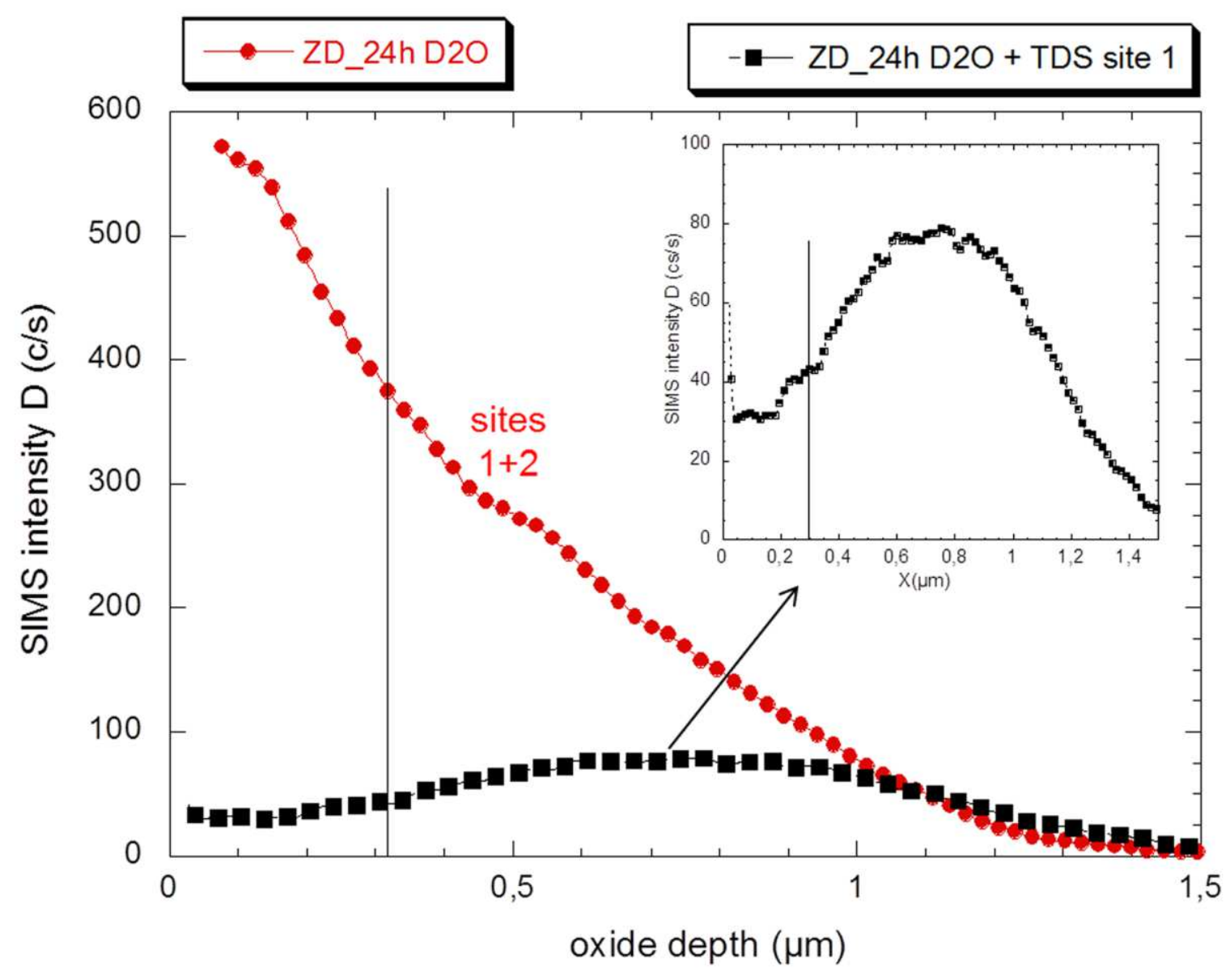


Figure 13: Deuterium thermal desorption spectra performed on two samples of zircaloy-4 - one oxidized during 50 days in $\mathrm{H}_{2} \mathrm{O}$ and then exposed 6 hours in ${ }^{2} \mathrm{H}_{2} \mathrm{O}$ (red circles) at $360^{\circ} \mathrm{C}$.- the second oxidized during 171 days in $\mathrm{H}_{2} \mathrm{O}$ and then exposed 6 hours in ${ }^{2} \mathrm{H}_{2} \mathrm{O}$ (dark squares) at $360^{\circ} \mathrm{C}$.

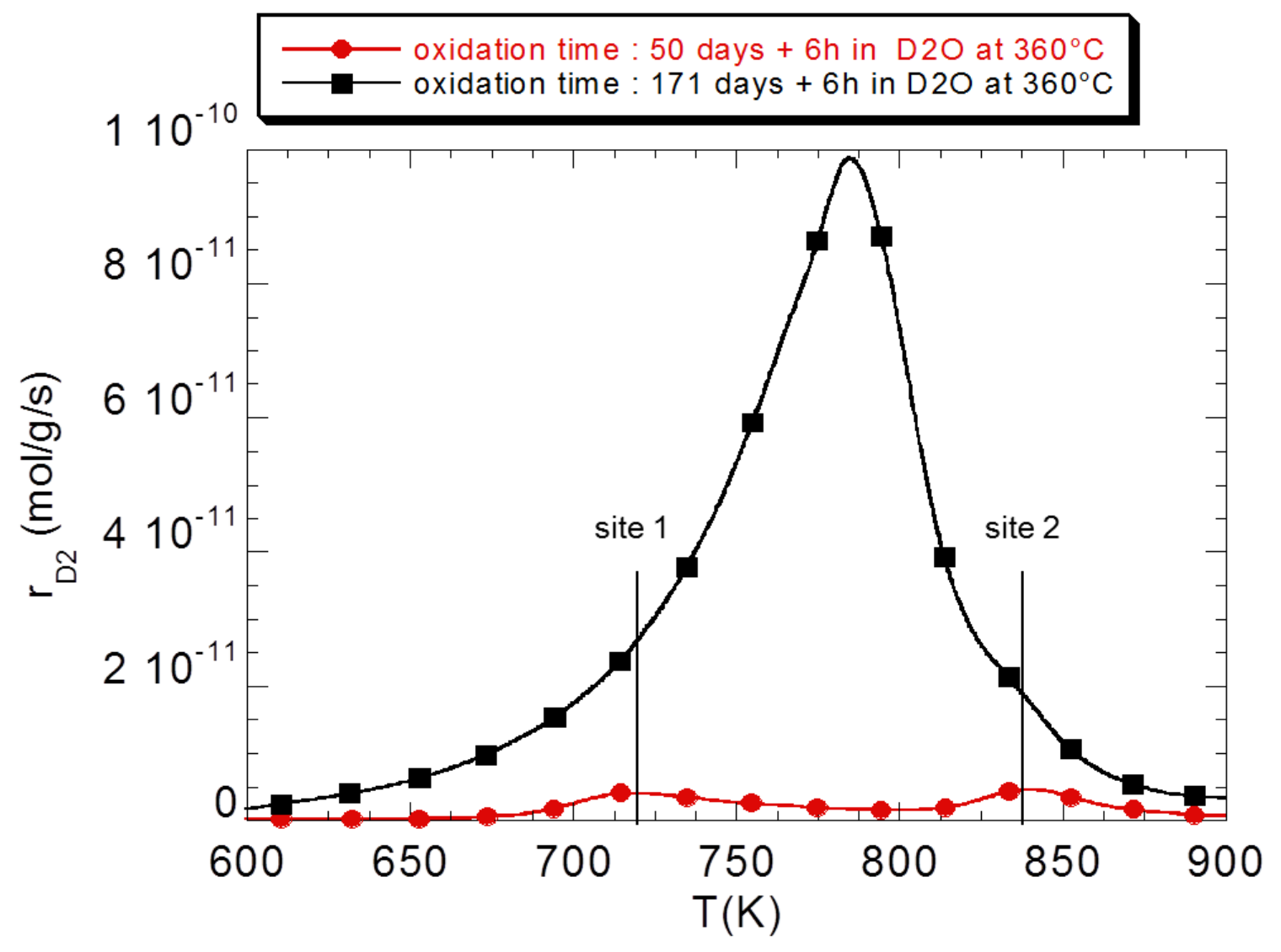


Figure 14 : SIMS profiles of deuterium after a thermal transient and a 6-hours exposure in heavy water on pre-corroded Zircaloy-4 samples in the pre-transition domain. $\mathrm{C}_{\mathrm{s}}$ represents the deuterium content at the entrance of the dense part of the oxide.

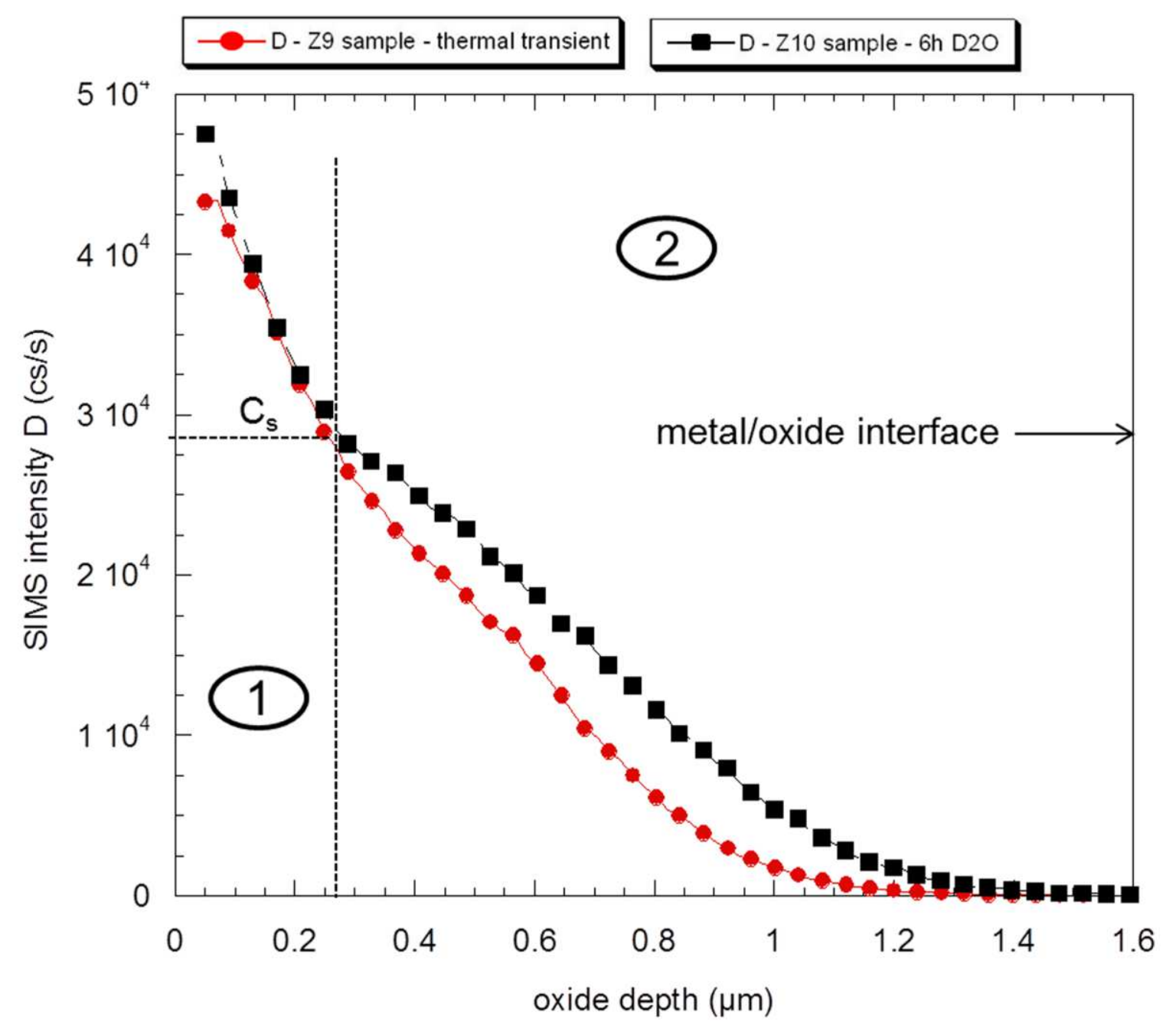


Figure 15 : Inner part of experimental curves obtained after thermal transient and 6 hours of exposure in heavy water on pre-transition oxide films associated with the fitted curves calculated with CAST3M code.

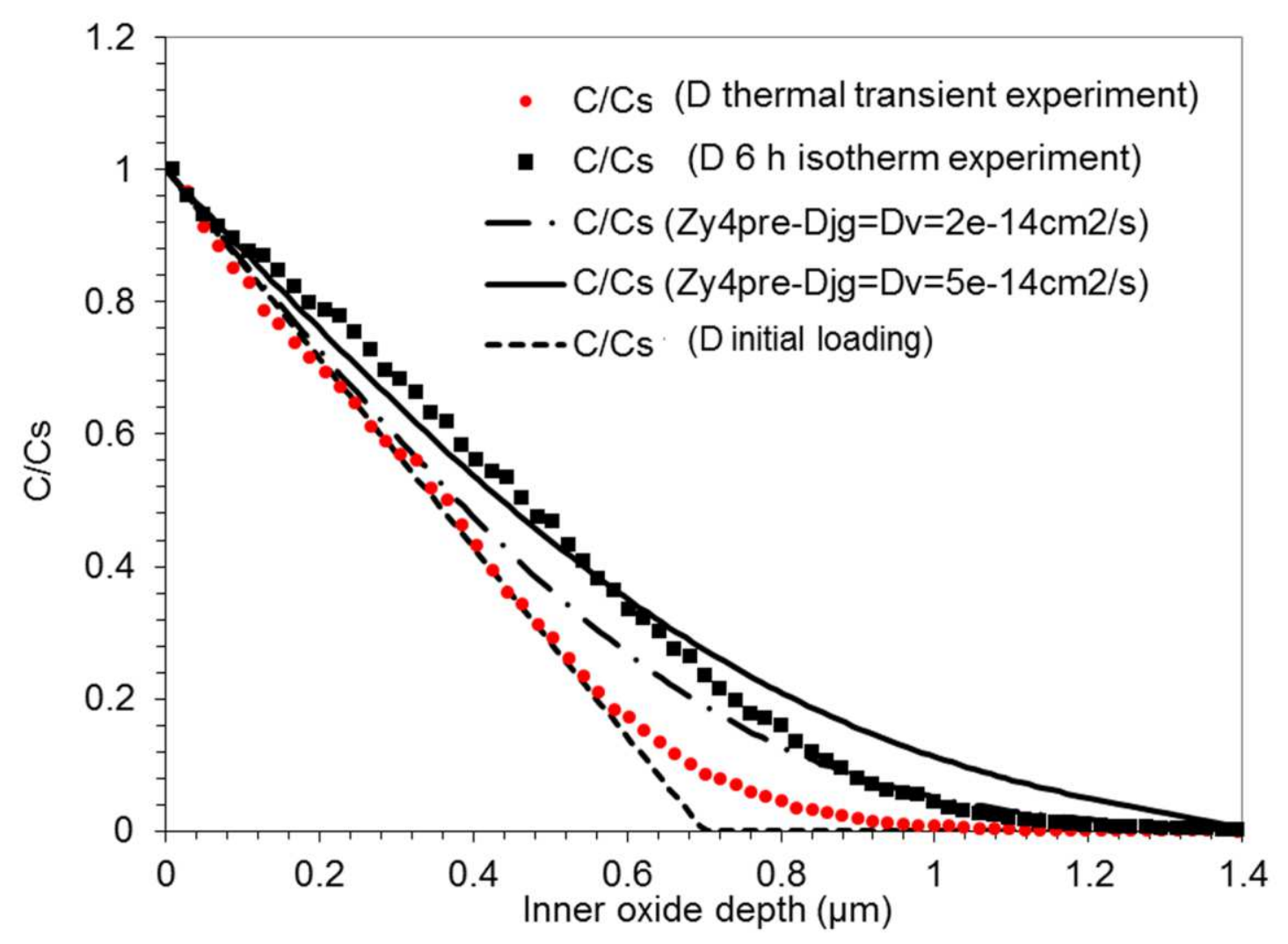


Figure 16 : a) Principle of ERDA technique _ b) Scanning electron micrograph of a tapered view of the post-transition Z6 sample. c) Hydrogen cartography obtained with ERDA. d) Typical ERDA spectrum from the area defined by the red continuous line in hydrogen cartography in Figure 16c. Heterogeneous hydrogen distribution in the metallic part of the sample can be associated with Figure $3 \mathrm{~b}$ and the presence of zirconium hydrides.

a)
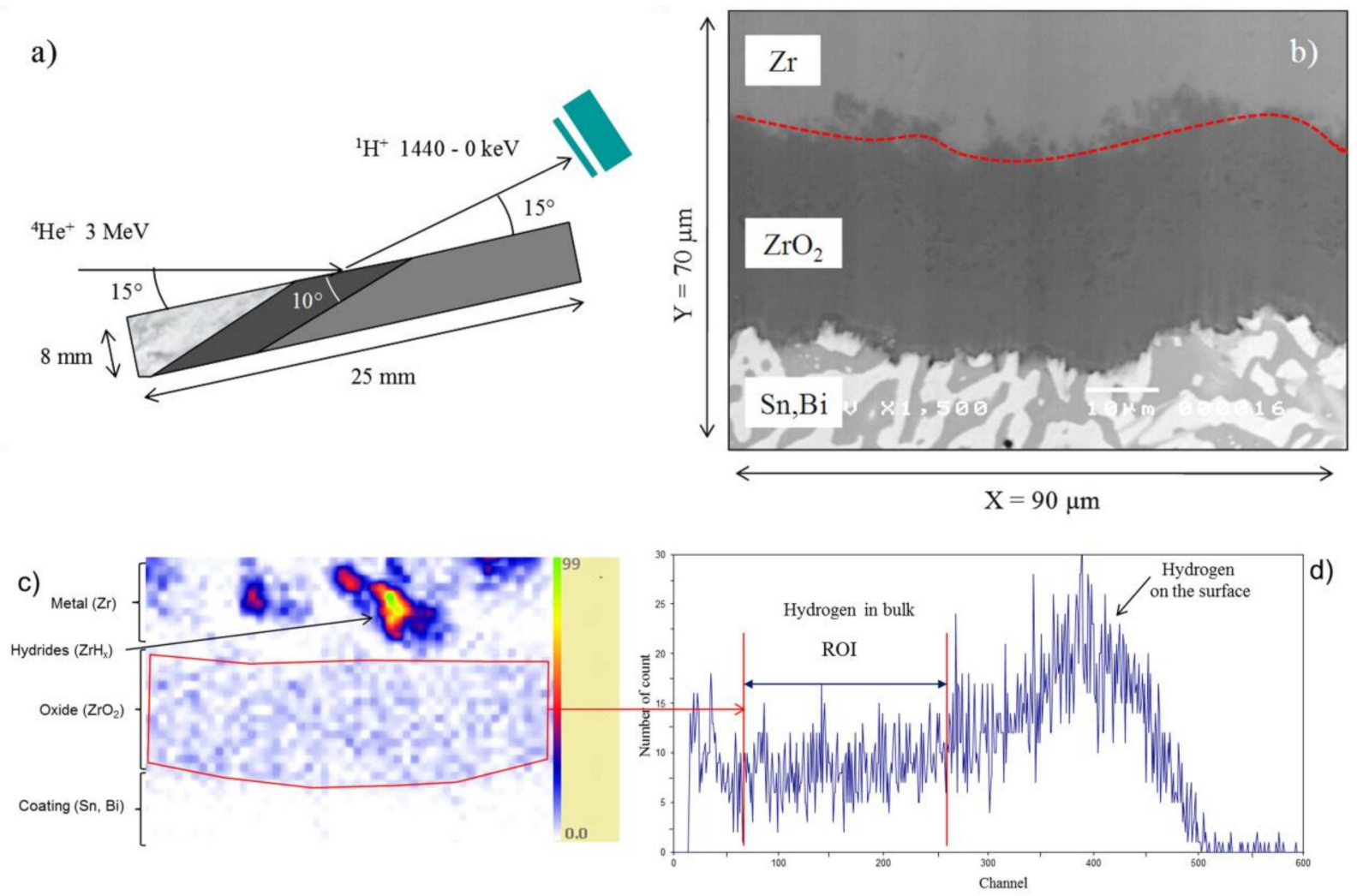
Figure 17 : Determination of the hydrogen concentration at the entrance of the inner oxide $\left(C_{s}\right)$ deduced from the ERDA measurements (C(ERDA)).

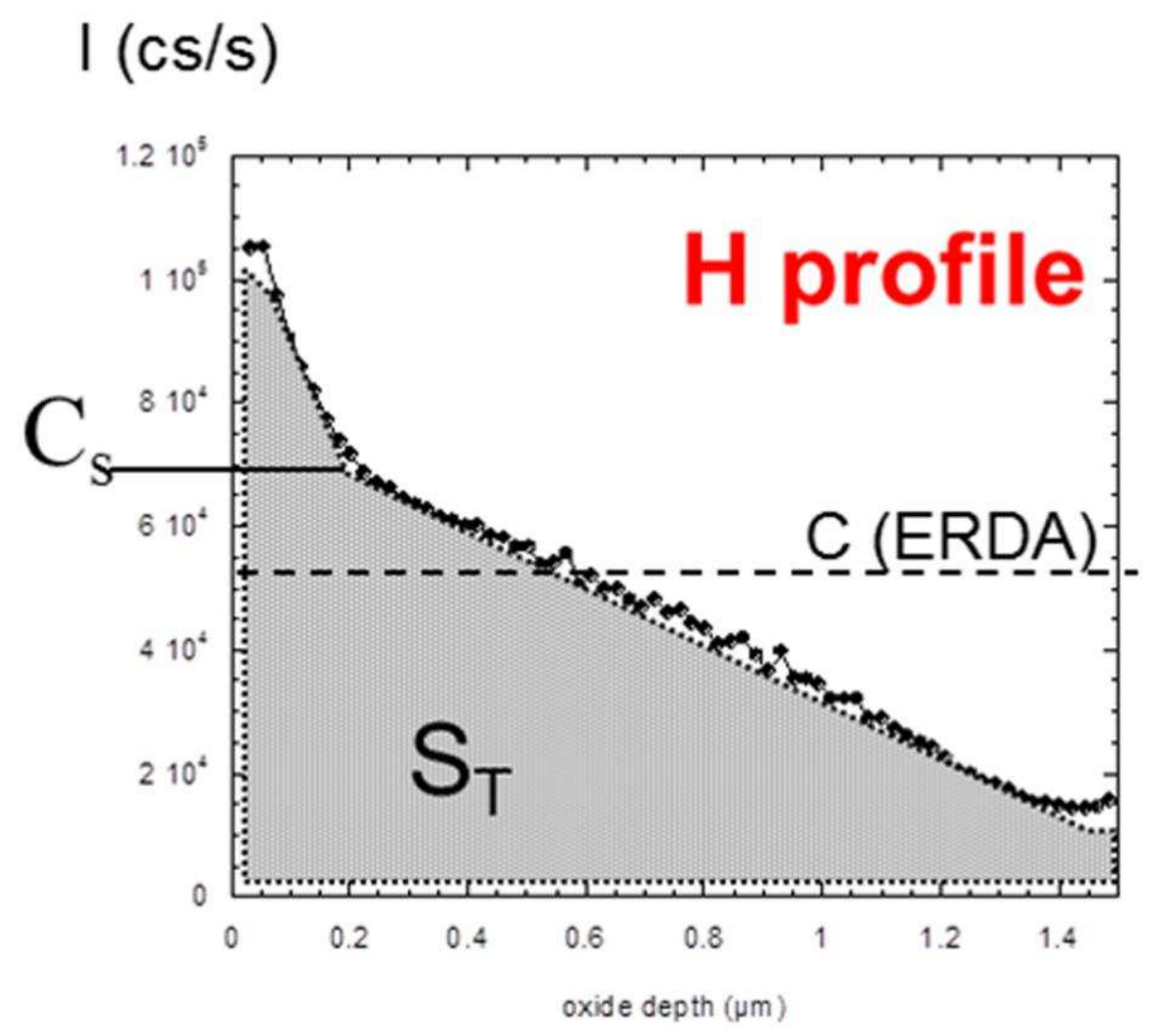


Figure 18 : Arrhenius plot of the diffusion coefficients of hydrogen isotopes in the oxide layer formed on zirconium alloys. Comparison with the literature data.

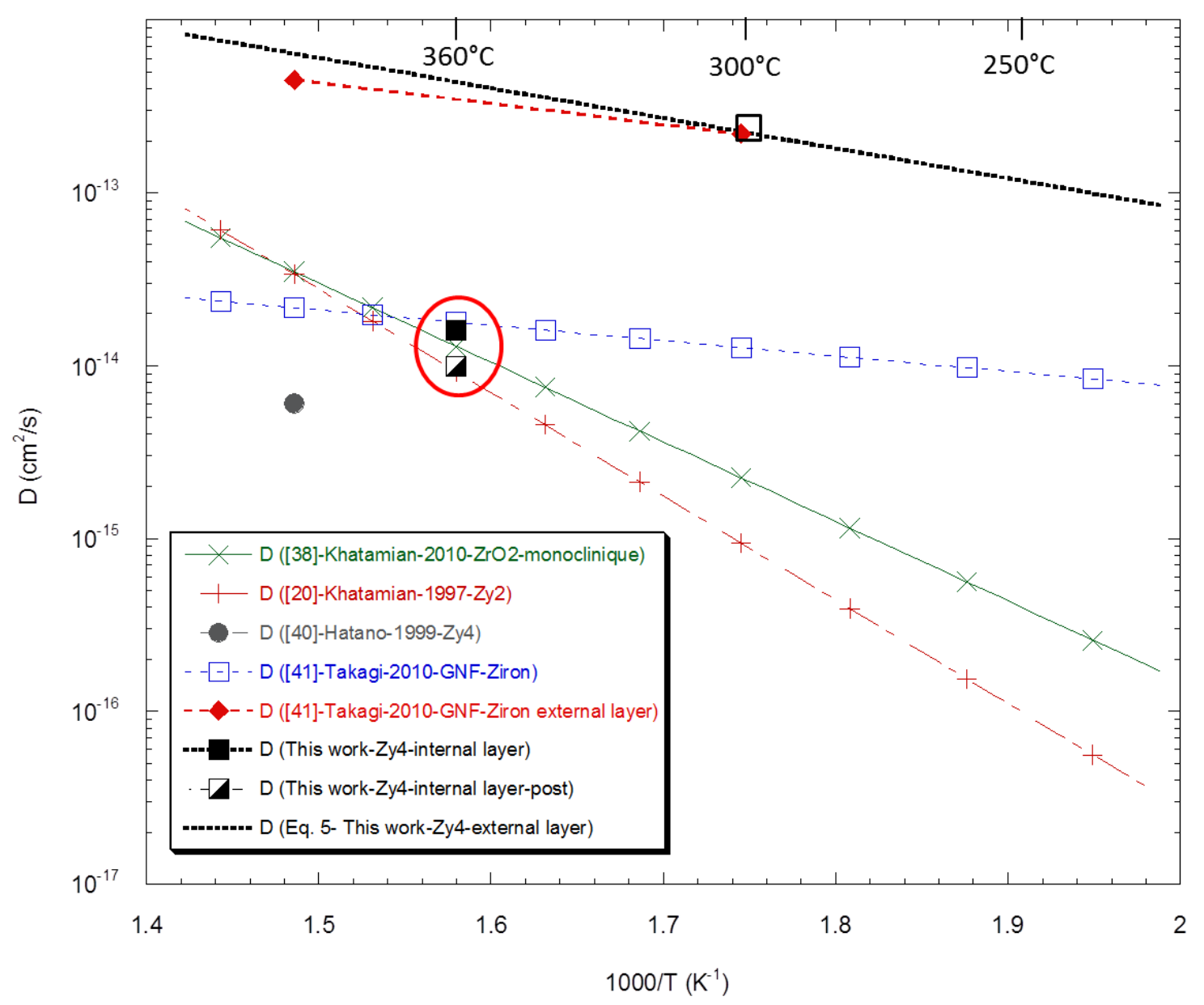


Tables :

Table 1: Chemical composition of Zircaloy-4 sheet (wt\%)

\begin{tabular}{|l|l|l|l|l|l|l|}
\hline $\begin{array}{l}\text { Alloying } \\
\text { elements }\end{array}$ & $\mathrm{Fe}$ & $\mathrm{Cr}$ & $\mathrm{Sn}$ & $\mathrm{O}$ & $\mathrm{H}$, wt ppm & $\mathrm{Zr}$ \\
\hline Zircaloy-4 & 0.22 & 0.11 & 1.46 & 0.13 & 21 & Bal. \\
\hline
\end{tabular}


Table 2 : Test matrix with the name of the specimen, the corrosion duration, the oxide thickness, the isotopic exposure times in $\mathrm{D}_{2} \mathrm{O}$, the SIMS analyses and TDS experiments.

\begin{tabular}{|c|c|c|c|c|c|c|c|}
\hline Specimen & $\begin{array}{l}\text { Corrosion } \\
\text { duration } \\
\text { (days) }\end{array}$ & $\begin{array}{l}\text { Oxide } \\
\text { thickness } \\
(\mu \mathrm{m})^{*}\end{array}$ & $\begin{array}{l}\text { Fusion } \\
\text { measurements }\end{array}$ & $\begin{array}{l}\text { Kinetics } \\
\text { domain }\end{array}$ & $\begin{array}{l}\text { Isotopic } \\
\text { exposure } \\
\text { in heavy } \\
\text { water } \\
\left(\mathrm{D}_{2} \mathrm{O}\right)\end{array}$ & Objective & $\begin{array}{l}\text { Thermal } \\
\text { Desorption } \\
\text { Spectroscopy }\end{array}$ \\
\hline $\mathrm{Z1}$ & 50 & 1.5 & - & \multirow{2}{*}{$\begin{array}{l}\text { pre } \\
\text { transition }\end{array}$} & - & $\begin{array}{l}\text { ex-situ } \\
\text { kinetic } \\
\end{array}$ & - \\
\hline $\mathrm{Z} 2$ & 50 & 1.5 & - & & - & & - \\
\hline $\mathrm{Z3}$ & 50 & 1.6 & yes & \multirow{5}{*}{$\begin{array}{l}\text { pre } \\
\text { transition }\end{array}$} & - & \multirow{5}{*}{$\begin{array}{l}\text { SIMS } \\
\text { analysis }\end{array}$} & - \\
\hline ZD_TT & 50 & 1.6 & - & & TT & & yes \\
\hline Z4_6h & 50 & 1.7 & - & & 6 hours & & yes \\
\hline ZD_24h & 50 & 1.7 & - & & 24 hours & & yes \\
\hline Z5 & 50 & 1.6 & - & & 7 days & & - \\
\hline Z6 & 171 & 3.6 & yes & \multirow{4}{*}{$\begin{array}{l}\text { post } \\
\text { transition }\end{array}$} & - & \multirow{4}{*}{$\begin{array}{l}\text { SIMS } \\
\text { analysis }\end{array}$} & - \\
\hline Z7_TT & 171 & 3.6 & - & & TT & & \\
\hline Z7_6h & 171 & 3.6 & - & & 6 hours & & yes \\
\hline Z8 & 171 & 3.6 & - & & 7 days & & - \\
\hline
\end{tabular}

*Oxide thicknesses are deduced from weight gains. 
Table 3 : Hydrogen contents (wt ppm) absorbed by the Zircaloy-4 alloy during corrosion in PWR conditions, hydrogen concentrations in the material and $\mathrm{r}_{\mathrm{H}}$, the Hydrogen Pick-Up Fraction.

\begin{tabular}{|l|l|l|l|l|l|l|}
\hline Specimen & $\begin{array}{l}\text { Corrosion } \\
\text { duration } \\
(\text { days })\end{array}$ & $\begin{array}{l}\text { Oxide } \\
\text { thickness } \\
(\mu \mathrm{m})^{*}\end{array}$ & $\begin{array}{l}\text { Kinetic } \\
\text { domain }\end{array}$ & $\begin{array}{l}\mathrm{H} \text { content } \\
(\mathrm{wt} \text { ppm })^{* *}\end{array}$ & $\begin{array}{l}C_{\mathrm{H}_{-} \text {ERDA }}^{\mathrm{ZrO}{ }_{2}} \\
\left(\mathrm{~mol}^{-3} \mathrm{~cm}^{-3}\right) * *\end{array}$ & $\begin{array}{l}\mathrm{r}_{\mathrm{H},} \\
\text { Hydrogen } \\
\text { Pick-Up } \\
\text { Fraction (\%) }\end{array}$ \\
\hline $\mathrm{Z3}$ & 50 & 1.6 & $\begin{array}{l}\text { pre- } \\
\text { transition }\end{array}$ & 12 & $7.8 \times 10^{-5}$ & 11.7 \\
\hline $\mathrm{Z6}$ & 171 & 3.6 & $\begin{array}{l}\text { post- } \\
\text { transition }\end{array}$ & 30 & $2.0 \times 10^{-4}$ & 13 \\
\hline
\end{tabular}

** Hydrogen contents in the metal are calculated from fusion measurements and were reduced to a corresponding one-sided corrosion (the nominal content of the alloy being deduced). 
Table 4 : Deuterium amount trapped in all the sites for Zy4 samples oxidized 50 and 171 days in PWR conditions.

\begin{tabular}{|l|l|l|}
\hline Exposure times and medium & $50 \mathrm{~d} \mathrm{H}_{2} \mathrm{O}+6 \mathrm{~h} \mathrm{D}_{2} \mathrm{O}$ & $171 \mathrm{~d} \mathrm{H}_{2} \mathrm{O}+6 \mathrm{~h} \mathrm{D}_{2} \mathrm{O}$ \\
\hline $\begin{array}{l}\text { Deuterium amount trapped in all } \\
\text { the sites (mol/g) }\end{array}$ & $\sim \mathbf{8} \mathbf{1 0}^{-9}$ & $\sim \mathbf{1 . 1 0} \mathbf{1 0}^{-\mathbf{-}}$ \\
\hline
\end{tabular}


Table 5 : Isotopic exposure times in heavy water $\mathrm{D}_{2} \mathrm{O}$ in the fast water-cooled autoclave.

\begin{tabular}{|l|l|l|l|}
\hline Specimen & $\begin{array}{l}\text { Corrosion } \\
\text { duration } \\
\text { (days) }\end{array}$ & $\begin{array}{l}\text { Oxide } \\
\text { thickness } \\
(\mu \mathrm{m})\end{array}$ & $\begin{array}{l}\text { Isotopic exchange } \\
\text { with } \mathrm{D}_{2} \mathrm{O}\end{array}$ \\
\hline $\mathrm{Z9}$ & 50 & 1.7 & thermal transient \\
\hline $\mathrm{Z10}$ & 50 & 1.6 & 6 hours \\
\hline
\end{tabular}


Table 6 : Average concentrations of hydrogen in oxides measured by ERDA, $C_{\mathrm{H} \_ \text {ERDA }}^{\mathrm{ZrO}}$, and estimation of the $\mathrm{C}_{\mathrm{s}}$ concentration of hydrogen at the entrance of the inner part of the oxide film.

\begin{tabular}{|l|l|l|l|l|}
\hline $\begin{array}{l}\text { analysed } \\
\text { sample }\end{array}$ & $\begin{array}{l}\text { oxide } \\
\text { thickness } \\
(\mu \mathrm{m})\end{array}$ & $\begin{array}{l}\text { average } \mathrm{H} \\
\text { content } \\
\text { in } \mathrm{ZrO}_{2} \\
(\mathrm{wt} \mathrm{ppm})\end{array}$ & $\begin{array}{l}C_{\mathrm{H} \_ \text {ERDA }}^{\mathrm{ZrO} 2} \\
\left(\mathrm{~mol} . \mathrm{cm}^{-3}\right)\end{array}$ & $\begin{array}{l}C_{\mathrm{s}} \\
\left(\mathrm{mol}_{\mathrm{cm}} \mathrm{cm}^{-3}\right)\end{array}$ \\
\hline $\begin{array}{l}\text { pre-transition } \\
\text { oxide }\end{array}$ & 1.6 & 237 & $1.33 \times 10^{-3}$ & $1.83 \times 10^{-3}$ \\
\hline $\begin{array}{l}\text { post-transition } \\
\text { oxide }\end{array}$ & 3.6 & 324 & $1.83 \times 10^{-3}$ & $2.16 \times 10^{-3}$ \\
\hline
\end{tabular}


Table 7 : Hydrogen contents in $\mathrm{Zr}$ and $\mathrm{ZrO}_{2}$ and hydrogen apparent diffusion coefficient $\left(D_{\mathrm{a}}\right)$ at $360^{\circ} \mathrm{C}$ based on ERDA analyses and fusion measurements. Comparison with Cast $3 \mathrm{~m}$ calculations.

\begin{tabular}{|l|l|l|l|l|l|}
\hline Oxide & $\begin{array}{l}n_{\mathrm{H}-\mathrm{Zusion}}^{\mathrm{Zr}+\mathrm{ZrO}} \\
\left(\mathrm{mol.cm}{ }^{-2}\right)\end{array}$ & $\begin{array}{l}n_{\mathrm{H}-\mathrm{ZRDA}}^{\mathrm{ZrO}} \\
\left(\mathrm{mol.cm}{ }^{-2}\right)\end{array}$ & $\begin{array}{l}n_{\mathrm{H}}^{\mathrm{Zr}} \\
\mathrm{from} \quad(\mathrm{Eq} . \quad 9) \\
\left(\mathrm{mol} . \mathrm{cm}^{-2}\right)\end{array}$ & $\begin{array}{l}D_{\text {a_ERDA }} \\
\left(\mathrm{cm}^{2} / \mathrm{s}\right)\end{array}$ & $\begin{array}{l}D_{\text {a_Cast3m }} \\
\text { with Cast3m } \\
\left(\mathrm{cm}^{2} / \mathrm{s}\right)\end{array}$ \\
\hline pre-transition & $1.83 \times 10^{-6}$ & $2.1 \times 10^{-7}$ & $1.62 \times 10^{-6}$ & $1.6 \times 10^{-14}$ & {$\left[2 \times 10^{-14} ; 5 \times 10^{-14}\right]$} \\
\hline post-transition & $4.49 \times 10^{-6}$ & $6.6 \times 10^{-7}$ & $3.82 \times 10^{-6}$ & $1.0 \times 10^{-14}$ & - \\
\hline
\end{tabular}

